\title{
Cross-border Effects in Interconnected Electricity Markets - An Analysis of the Swiss Electricity Prices
}

\author{
Dogan Keles ${ }^{\mathrm{a}, *}$, Joris Dehler-Holland ${ }^{\mathrm{a}}$, Martin Densing ${ }^{\mathrm{b}}$, Evangelos Panos $^{\mathrm{b}}$, \\ Felix Hack ${ }^{\mathrm{a}}$ \\ ${ }^{a}$ Karlsruhe Institute of Technology, Chair of Energy Economics, \\ Hertzstraße 16, D-76187 Karlsruhe, Germany \\ ${ }^{b}$ Paul Scherrer Institute, Energy Economics Group, Forschungsstrasse 111, 5232 Villigen \\ PSI, Switzerland
}

\begin{abstract}
Electricity markets in Europe become increasingly interconnected due to new grid connections and market coupling regulations. This paper examines the interdependencies between the Swiss electricity market and those of neighboring countries. The Swiss market serves as a good example for a smaller electricity market which is increasingly affected by developments in the large neighbouring countries. To study these cross-border effects, especially those on Swiss electricity prices, we apply two different methodologies, an econometric and a Nash-Cournot equilibrium model.

The analyses show that the Swiss electricity price correlates strongly with the German electricity price in the summer, but tends to follow the French electricity price in the winter. Another finding is that gas prices and the electricity load of neighboring countries have a significant influence on prices. In particular, the load of France and Italy is driving up Swiss prices in the winter, while the German electricity demand and renewable energy generation have a larger influence on Swiss prices in the summer.
\end{abstract}

Keywords: electricity prices, time series analysis, Swiss electricity market, cross-border effects, Nash-Cournot equilibrium

\section{Introduction}

Switzerland, geographically located in the heart of Europe, has many grid interconnector links with a total capacity more than $7 \mathrm{GW}$ to the electricity networks of Germany, Austria, France and Italy [1]. The existing transmission services to neighbouring countries are auctioned in implicit and explicit auctions. In this way, the load and generation of neighbouring countries as well as national price drivers, such as the electricity demand, influence the Swiss market prices. Price differences between market areas with cross-border electricity trade are caused by the limited capacity of cross-border interconnectors. International trade, however, reduces price differences between market areas.

\footnotetext{
* Corresponding author

Email address: dogan.keles@kit.edu (Dogan Keles)
} 
The electricity prices in Switzerland and in the neighbouring countries France, Italy and Germany are influenced by various factors. Both, demand and supply side factors play an important role. For the German electricity market, the installed capacities of intermittent renewable energy sources (RES), such as wind and solar power, have significantly increased over the last decade and contributed $38.2 \%$ to the total electricity production in 2017 2. German electricity production depends also on lignite $(24.3 \%)$, hard coal $(14.8 \%)$, nuclear energy $(13.1 \%)$ and natural gas $(8.9 \%)$. Because of this composition of the German power production, renewable electricity production and fuel prices are important factors in the formation of electricity prices. France, on the other hand, covers a large part of its electricity demand from nuclear energy and hydropower (2017: nuclear $71.6 \%$, hydropower $10.1 \%$ ) 3. Due to the high number of electric heaters, demand in France is more temperature-dependent than in any other country leading to load peaks in the winter. Hence, in France peak demand is an important price setting factor. Regarding the Italian electricity supply, it can be noted that the high production of electricity from gas (2016: $69 \%$ of thermal electricity generation) leads to a high price level. The higher prices in Italy in turn results in large imports from neighbouring countries whose electricity wholesale prices are significantly lower. The imports (11.1 $\%$ of demand coverage in 2016) have a price dampening effect in Italy [4, but due to limited import capacities the Italian price remains at high level most of the time. In addition, the share of RES in electricity supply is also increasing, especially from solar energy [5] affecting residual load and electricity prices.

These characteristics of the market areas are reflected in the respective price curves, in which sharp price increases or price drops can be observed depending on the influencing factor. However, such price impacts are not only limited to the market area where a specific characteristic can be found, but are also observed in the neighbouring markets. This is mainly due to large interconnector capacities and the intensifying market coupling, which enhance cross-border electricity flows. In more detail, if, for instance, there is a high feed-in of wind or solar energy in Germany and at the same time a low load, prices can fall significantly in Germany and also in the connected market areas. Additionally, the winter load peaks in France do not only lead to very high French wholesale electricity prices, but also to high electricity prices in the neighbouring countries in the related time periods. Therefore, the French load seems to be an important cross-border driver, especially in the winter season, whose effect is worth to be investigated differentiating between the seasons.

In this paper, we analyze the connected electricity markets in Central Western Europe arguing that they have a considerable interdependence as a result of the tight links causing strong interactions between electricity prices of the different countries. Based on the example of Switzerland, we analyze influencing factors of large neighboring countries, such as demand and renewable feed-in in Germany and France, on electricity prices of a smaller country. The influencing factors originating from the neighbours are called "cross-border drivers" in the following and the related impact is named as "cross-border effect".

In the literature, there are several analyses about cross-border effects on the electricity market in general (see Section 2), but only a few studies focus on the effects of variables from abroad on domestic electricity prices. In the literature, only a single cross-border driver is analyzed and this is done mainly for artificial energy systems. This paper contributes to analyses of cross-border 
effects on electricity prices by considering multiple drivers in a real-world energy system, especially for the case of an asymmetric market area, where a small market is influenced by large neighbours (i.e. Germany, France and Italy). Furthermore, we differentiate our analyses on price drivers for the winter and summer season ${ }^{17}$, as the values and therefore the effects of cross-border and domestic drivers can strongly vary among different seasons.

Different factors can be considered for the analysis of the price effects, especially several cross-border drivers can be taken account for the Swiss electricity market. Therefore, by analyzing the commercial exchange flows with the neighbouring and comparing price trends, at first, a statistical analysis of Swiss electricity prices is carried out to uncover their inherent trends and to examine fundamental determinants (Section 3). On the basis of these findings, econometric models based on multivariate regression are formulated that can be classified as ARIMAX models (Section 4.1). The ARIMAX models then are used to map Swiss day-ahead market prices on price drivers, also on those originating from the neighboring markets.

Additionally, a Nash-Cournot equilibrium model (Section 4.2) of the Swiss electricity market is applied to cross-check and validate the results of the econometric model and to detect robust drivers as well as to detect non-linearities in the price effects (Section 5). The equilibrium model simulates the CentralWestern European countries considering transmission capacities. As it models interactions between different countries and formulates a demand-elastic price curve, it delivers on non-linearities of the system. By comparing the results of the linear econometric mode $\left.\right|^{2}$ to the fundamental simulation (equilibrium) model, we can validate the results of the econometric model in general and support the use of econometric model for the detailed analyses of seasonal crossborder effects. After presenting the detailed results of the models, we summarize and discuss the main findings of the analyses in the conclusions chapter (Section 7).

\section{Literature review}

Electricity price models have been developed of a large variety of goals, horizons and markets. Therefore, many different methods can be found in electricity price analysis literature. In the following, we provide an literature overview of applications of different types of methods and then set the focus on literature about cross-border effects.

\subsection{Fundamental and Nash-Cournot equilibrium models for price analysis}

Equilibrium models for electricity price analysis are usually fundamental models that match power production options with power demand based on a microeconomic principle of the involved agents. Perfect-competition is one of the

\footnotetext{
${ }^{1}$ In this study we group autumn to the winter season and spring to the summer season mainly due to similarities in the profiles of PV and load data, two main parameters that effect prices.

${ }^{2}$ The econometric model can cover non-linearities only indirectly due to desperate modeling of each hour of the day. As a consequence, tThe combination of all model outputs is then non-linear.
} 
most commonly used approaches, where all agents are price-takers and marginal cost pricing is applied.

The analysis of 6 for day-ahead and intraday prices in Germany uses a fundamental model under the perfect-competition assumption, such that resulting prices have still to be adjusted considerably to match empirical prices. Examples of such (ad-hoc) driving adjustments are the difference between installed capacity and demand, which accounts for the scarcity of supply, and the rate of change in demand over the load periods, which accounts (as a proxy) for the ramp-up and -down costs of thermal production.

To lower the burden of technology detail but still to keep a marginal-cost approach, the follow-up analysis of [7] on futures prices in Germany uses a so-called parsimonious fundamental equilibrium model with a piece-wise linear approximation of the merit-order curve. One of the main results of $[7$ is that the major influence factor for the price drop in Germany during 2007-2013 is the low $\mathrm{CO}_{2}$ price, then followed by renewable production, a drop in electricity demand, and a reduction in installed conventional capacity.

A different microeconomic principle for the involved agents in electricity markets is the Cournot and supply function equilibrium, where power producers can withhold capacity and deviate from marginal cost pricing 8]. Models that deviate from the marginal cost pricing without assuming ad-hoc price mark-ups are for example Nash-Cournot competitive equilibrium models [8] and supply function equilibria 9, with the latter being analytically more complex and usually used for stylized analyses. Nash-Cournot modeling is used in 10 to explain today's EPEX prices; it was found that Nash-Cournot leads to too high prices compared to the observed prices in the EPEX market. A similar finding is also confirmed by other authors. For example in 11 different strategic behaviours of agents and their impact on German electricity prices are analyzed: perfect competition, Cournot competition, and a leader and follower (bi-level) game. It was found that perfect competition is the best fit to today's prices, Cournot competition leads to high prices compared with data, and the bilevel approach - having intermediate prices - matches better the prices in peak-load hours. Similarly, in [12, 13, 14] a game-theoretic bottom-up (fundamental) model with data from the European electricity market is applied.

In order to avoid inflated prices in the Nash-Cournot model as encountered by 12, 13, 14, conjectural variation approaches can be applied. For example, [15] uses such an approach to model the Spanish electricity market: the conjectural variation parameter, also called conduct parameter, lies in the interval $[0,1]$ — with zero denoting perfect competition and one denoting Cournot conjectures - is determined in a calibration mode to match historical prices.

In our approach of Nash-Cournot equilibrium modeling, we use a conjectural variation model of Switzerland and the surrounding countries to investigate the effects of the neighbouring markets on Swiss prices. It is also a fundamental model that incorporates technical details of power production, especially of thermal dispatch constraints. The conduct parameter of conjectural variation model is used to match historical prices (see also section 4.2).

As our Nash-Cournot equilibrium approach is able to model the competitive markets of the the surrounding countries and their technical constraints, it is suitable to analyse the cross-border factors and their impacts on Swiss electricity prices. 


\subsection{Econometric models for electricity prices and cross-border effects}

Econometric models are frequently used for the analysis of electricity prices in the recent years. This model family can further be divided into subfamilies, including regression models, artificial intelligence models and Markov process based models [16]. While models of the last two types are often used for forecasting prices, these are usually unsuitable for analyzing past prices. Thus, especially in artificial intelligence models, the complex mathematical structure of the models does not allow the influence of individual explanatory variables to be estimated.

In electricity price literature, regression models are a popular choice. However, they are often used as reference models for the comparison with more complex models. Still, multiple regression models provide accurate results. For instance, [17 use a multi-linear regression approach to forecast electricity prices in California, using load, capacity, weather data and strategic information as explaining variables. [18] show that a non-parametric regression does not perform worse than an artificial neural network for the Spanish market. Again, they use data on load, renewable generation and weather to predict the prices.

Popular model frameworks in price modeling literature also are ARIMAand GARCH-type models, both being econometric autoregressive models. They have been successfully applied many times (e.g. [19, 20, [21]) for price simulation, but do not allow to investigate the impact of fundamental factors. Some of the researcher extend their time series models with fundamental explaining variables. 21] and [22] find that external variables have significant influence on electricity prices. 23 and 24 show evidence for the effect of PV generation on Italian prices or wind generation on Irish prices, respectively.

To address and analyse the effects of different regressors, we use also regression models in our approach and extend them by autoregressive components resulting in an ARIMAX approach.Thereby, we focus on the regressors originating from other countries and name them as cross-border factors.

Cross-border factors and their effects are rarely taken into account in electricity price literature. 25] point out that they should be included in a price analysis using regression in order to improve the results. Due to the volumes that may be transferred from one market to another and the modified bid functions, cross-border trading of electricity influences the market outcomes of the interconnected countries [26]. With increasing available transfer capacity, the prices of the markets converge and total welfare is increased. This effect is also observed in real-world markets: 27 empirically shows the convergence of electricity prices for several pairs of countries in the common European market.

The effects of individual market-external factors on the electricity prices of a market were also examined. In an agent-based simulation, 28, shows that the introduction of a minimum price for $\mathrm{CO}_{2}$ certificates in the UK electricity market significantly influences prices in neighbouring France. 29] and [30] use empirical studies to investigate the influence of the German feed-in tariff for renewable energy production and the resulting massive capacity expansion on other markets. Both find a significant influence of PV feed-in on the French electricity price. While the average price falls due to the increasing feed-in, the volatility of the prices rises 30 . 29 also show the influence of fluctuating feedin prices in Germany on hourly prices, but also point to the restrictive effect of limited transmission capacity. In their electricity price prediction model, 31. 
conclude that the use of price information of other markets improves the forecast accuracy. Hereby, they only use historical prices and no fundamental market data.

[32] use a linear multiple regression to analyze the Swiss market, focusing explicitly on cross-border effects from Germany, such as renewable generation. In addition, they model seasonal components in order to be able to make statements about the influence of individual variables over time. They conclude that the Swiss electricity price is strongly influenced by German fundamentals, which should be taken into account in energy policy decisions.

[32] specifically investigate the impact from cross-border effects from Germany on the Swiss electricity market. They use a regression model with numerous explaining variables including German renewable production and load. They find strong time-varying cross-border effects of German fuel prices and renewable electricity production on Swiss prices. From the results, they suggest Swiss policy makers specific subsidies for PV and hydro power investments. However, they include the German renewable power production as the only cross-border price driver.

Hence, it can be stated that the effects of some cross-border drivers have been investigated in the literature. However, the studies are limited to the analysis of a either a single factor or a single market. In addition, the effect on average prices or long-term prices is usually examined. Our approach, however, analyzes the effect of multiple cross-border factors from several neighbouring countries on the hourly electricity spot prices of a domestic market. For this purpose, a asymmetric market constellation has been chosen, in which the effects of large neighbouring market areas on a smaller electricity market become more visible. This numerical analysis of the cross-border drivers focuses on the effects on short-term electricity prices.

\section{Data and statistical analysis of Swiss prices}

The data basis for the following analyses is the period from $1^{\text {st }}$ January 2011 to $31^{\text {st }}$ December 2017 . The data originates from various databases that are open accessible for academic purposes. Demand data for all countries besides Switzerland comes from the transparency platform of ENTSO-E (2018b). For Switzerland, the load data provided by the national TSO Swissgrid is used. In particular, the published gross load excluding pump and own consumption of the power plants is applied to all following analyses and models. The day-ahead forecast for solar and wind power feed-in derived from the ENTSO-E (2018b). Fuel prices for coal and gas are provided by EPEX Spot (2018) in daily resolution. The data for weekends and holidays when fuels are not traded are set to the price of the previous workday. With the exception of the northern Italian price, price data come from EPEX Spot (2018), the operator of the stock exchanges in France, Germany and Switzerland. In the regarded period, Germany and Austria form a common market area without transmission bottlenecks at the common border. The German prices thus also represent the Austrian prices. The northern Italian prices originates from GME (2015).

The coupling of the electricity markets and the size of Switzerland's crossborder transmission capacities lead to a convergence of electricity prices with Germany or France. While the day ahead prices in France, Germany and 
Table 1: Literature on econometric and Nash-Cournot models for electricity prices and crossborder effects

\begin{tabular}{|c|c|c|c|}
\hline $\begin{array}{l}\text { Publ. } \\
\text { No. }\end{array}$ & Model type & Evaluated market(s) & Cross-border-effects \\
\hline$[6]$ & $\begin{array}{l}\text { Fundamental } \quad \text { (supply } \\
\text { stack) }\end{array}$ & Germany & - \\
\hline [7] & $\begin{array}{l}\text { Fundamental (piece-wise } \\
\text { linearized supply stack) }\end{array}$ & Germany & - \\
\hline 10 & Nash-Cournot & Germany & - \\
\hline 11 & $\begin{array}{lr}\begin{array}{l}\text { Fundamental, } \\
\text { competition } \\
\text { Cournot } \\
\text { (leader-follower) }\end{array} & \begin{array}{r}\text { Perfect } \\
\text { Nash- } \\
\text { Bi-level }\end{array} \\
\end{array}$ & Germany & - \\
\hline 12 & $\begin{array}{l}\text { Fundamental, Game- } \\
\text { theoretic }\end{array}$ & $\begin{array}{l}\text { Northwestern } \text { European } \\
\text { countries }\end{array}$ & $\begin{array}{l}\text { Transmission } \\
\text { (path-based) }\end{array}$ \\
\hline 13 & $\begin{array}{l}\text { Fundamental, Game- } \\
\text { theoretic }\end{array}$ & European countries & $\begin{array}{l}\text { Transmission } \\
\text { (path-based) }\end{array}$ \\
\hline 14 & $\begin{array}{l}\text { Fundamental, Game- } \\
\text { theoretic }\end{array}$ & European countries & $\begin{array}{l}\text { Transmission } \\
\text { (path-based) }\end{array}$ \\
\hline 15 & $\begin{array}{l}\text { Fundamental, Conjectural } \\
\text { Variation }\end{array}$ & Spain & - \\
\hline [17] & Multi-linear regression & California & - \\
\hline 18 & $\begin{array}{l}\text { Non-parametric } \quad \text { regres- } \\
\text { sion }\end{array}$ & Spain & - \\
\hline [19] & Multiple regression & Germany & - \\
\hline 20 & ARIMA & California, Spain & - \\
\hline 21 & $\begin{array}{l}\text { ARIMA, dynamic regres- } \\
\text { sion }\end{array}$ & PJM & - \\
\hline 22 & $\begin{array}{l}\text { Structural Vector Autore- } \\
\text { gressive }\end{array}$ & Great Britain & - \\
\hline 23 & Multi-linear regression & Italy & - \\
\hline 24 & $\begin{array}{l}\text { Unit commitment, } \\
\text { stochastic modeling }\end{array}$ & Ireland, Great Britain & - \\
\hline 25 & $\begin{array}{l}\text { Multiple, dynamic quan- } \\
\text { tile regression }\end{array}$ & Great Britain & - \\
\hline 27 & $\begin{array}{l}\text { Principal component anal- } \\
\text { ysis }\end{array}$ & Several European markets & Price analysis \\
\hline 28 & Agent based & Great Britain, France & $\begin{array}{l}\text { Influence of } \mathrm{CO} 2 \text { prices on } \\
\text { neighboring country }\end{array}$ \\
\hline 29 & Multi-linear regression & France, Germany & $\begin{array}{l}\text { Influence of renewable } \\
\text { generation on neighboring } \\
\text { market }\end{array}$ \\
\hline 30 & GARCH & France, Germany & $\begin{array}{l}\text { Influence of renewable } \\
\text { generation on neighboring } \\
\text { market }\end{array}$ \\
\hline 31 & $\begin{array}{l}\text { Regression model based } \\
\text { on price curves }\end{array}$ & Germany & $\begin{array}{l}\text { Historical prices of inter- } \\
\text { connected markets }\end{array}$ \\
\hline 32 & Multi-linear regression & Switzerland, Germany & $\begin{array}{l}\text { Influence of renewable } \\
\text { generation on neighboring } \\
\text { market }\end{array}$ \\
\hline 33 & $\begin{array}{l}\text { Asymmetric multi-stage } \\
\text { model }\end{array}$ & $\begin{array}{l}\text { Germany } \\
7\end{array}$ & - \\
\hline 34 & Fundamental & Germany & - \\
\hline 35 & $\begin{array}{l}\text { Fundamental, Game- } \\
\text { theoretic }\end{array}$ & European countries & $\begin{array}{l}\text { Transmission } \\
\text { (path-based) }\end{array}$ \\
\hline 36 & $\begin{array}{l}\text { Fundamental, Conjectural } \\
\text { Variation }\end{array}$ & Germany/Austria & - \\
\hline
\end{tabular}


Switzerland (data from EPEX Spot 2018) converge to each other in the summer, Swiss prices deviate from the German price and move towards Italian (data from GME 2015) price in the winter (see Figure 1). This leads to the hypothesis that load and other driving factors from neighbouring countries have different seasonal impact. The restrictive effect of the Italian electricity price on the Swiss price is also reflected in Figure 2, Apart from a few outliers, the Swiss price is limited upwards by the Italian price (green dotted line).
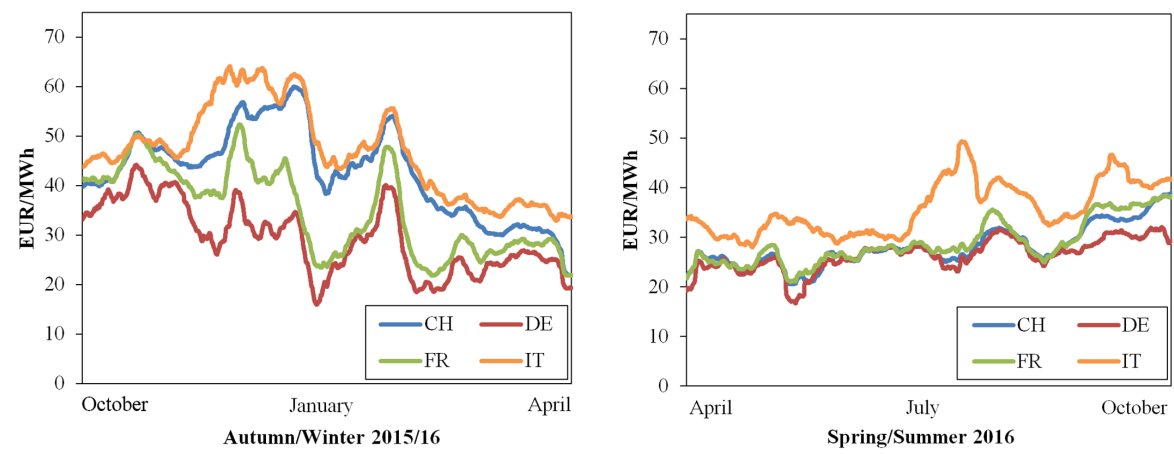

Figure 1: Moving 7-day average of electricity prices in Switzerland and its neighbouring countries (EPEX SPOT 2018; GME 2015) for Autumn/Winter 2015-2016 and Spring/Summer 2016 .

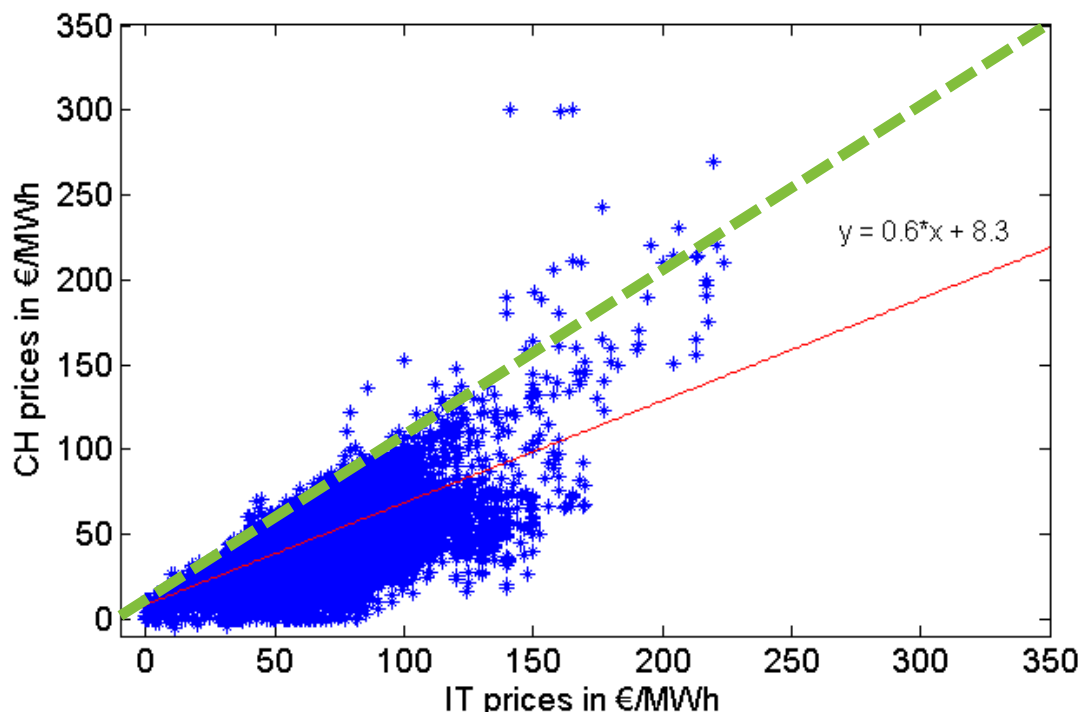

Figure 2: Scatter diagram of the Italian prices and the Swiss electricity prices

All prices have a falling trend until 2016 and reduced volatility/fluctuation observable from the decreasing standard deviation until 2015 with the exception of the year 2015 in Switzerland, France and Italy. After that, the trend reversed and Swiss electricity prices have risen significantly again until today 
Table 2: Descriptive statistics of Swiss electricity prices 2011-2018

\begin{tabular}{|r|r|r|r|r|r|r|r|r|}
\hline [EUR/MWh] & 2011 & 2012 & 2013 & 2014 & 2015 & 2016 & 2017 & 2018 \\
\hline mean & 56,18 & 49,52 & 44,73 & 36,79 & 40,30 & 37,88 & 46,00 & 52,22 \\
\hline std & 13,65 & 21,19 & 18,83 & 12,82 & 13,15 & 16,80 & 19,60 & 16,43 \\
\hline $\min$ & 0,00 & 0,00 & 0,00 & $-13,66$ & $-11,66$ & $-45,68$ & $-49,95$ & $-30,62$ \\
\hline $\max$ & 134,03 & 300,04 & 147,71 & 85,78 & 114,98 & 120,90 & 179,92 & 161,35 \\
\hline SPE & 4,12 & 2,34 & 2,38 & 2,87 & 3,06 & 2,25 & 2,35 & 3,18 \\
\hline
\end{tabular}

(see Table 23. This evolution of the prices can be attributed to various causes. In Germany, various studies have identified decreasing demand and decreasing $\mathrm{CO}_{2}$ and fuel prices as the driving factors behind price decline between 2011 and 2016, in addition to the increasing expansion of RES [7] 19]. The different tendencies and interrelations in the seasons will be examined later with the means of regression analysis.

The analysis of the correlation of electricity prices in neighbouring countries with the Swiss price confirms the previous observations: While a high correlation to prices in France and Germany can be observed especially in the spring and summer months, the linear relationship to the Italian market is weaker $(0.70)$. In winter, the correlations change: the Pearson correlation of Swiss prices to France and Germany decreases, the correlation with the Italian price increases compared to the summer (see Table 3).

Table 3: Correlation between Swiss and neighbouring countries' electricity prices

\begin{tabular}{lllllll}
\hline \hline & \multicolumn{2}{c}{ CH (Pearson correlation) } & \multicolumn{2}{c}{ CH (Spearman correlation) } \\
\hline Season & total & $\begin{array}{l}\text { spring/ } \\
\text { summer }\end{array}$ & $\begin{array}{l}\text { fall/ } \\
\text { winter }\end{array}$ & total & $\begin{array}{l}\text { spring/ } \\
\text { summer }\end{array}$ & $\begin{array}{l}\text { fall/ } \\
\text { winter }\end{array}$ \\
\hline FR & 0.83 & 0.91 & 0.80 & 0.93 & 0.94 & 0.90 \\
\hline DE/AT & 0.81 & 0.94 & 0.75 & 0.78 & 0.93 & 0.73 \\
\hline IT north & 0.73 & 0.70 & 0.76 & 0.72 & 0.69 & 0.75 \\
\hline \hline
\end{tabular}

However, the figures for France change when the Spearman rank correlation is considered instead: While the coefficient for Germany and Italy remains at the same level, the Spearman correlation coefficient between France and Switzerland is significantly higher in autumn and winter ( 0.80 and 0.90 respectively). This indicates a strong monotonous, non-linear correlation. Consequently, it can be deduced that the French electricity price has also a strong influence on the Swiss price, especially in the winter.

A deeper insight into this effect is provided by the analysis of the correlation of the influencing factors on the electricity prices of the different countries. The

\footnotetext{
${ }^{3}$ An interesting fact is that there are negative electricity prices since 2014, also in Switzerland. They happen when very low demand (not only in Switzerland, but also in Germany) meets high wind and solar production at the same time, which are handled primarily due to renewable support schemes. Even, when RES generators get a "small" negative price they do not switch off their production, as they would loose feed-in premiums that exist for instance in Germany. The operators of dispatchable capacities, such as nuclear power plants, also accept negative price for a couple of hours, as switching off a thermal power plant is mostly much costlier than accepting the negative price.
} 
electricity load in France correlates strongly with the Swiss load (Pearson 0.89) and the Swiss electricity price (Pearson 0.67). Particularly, high demand in France is accompanied by high prices on the Swiss electricity exchange. Figure 3 shows the Swiss load and electricity prices as a scatter diagram. The figure on the right shows the same values, adjusted by excluding all hours in which the French load is higher than $89 \mathrm{GW}$. It is noticeable that, with the addition of this condition, prices above 150 EUR are omitted. This means that very high electricity prices in Switzerland happen, when there is coincidental occurring of very high French demand and a high demand in CH. The average price in hours with a load of over 89 GW in France is 120 EUR. A closer analysis shows that both French peak loads and high Swiss prices occurred around 29 February 2012, while temperatures in France were unusually low (Réseau de Transport d'Electricité 2013). Therefore, it could be confirmed that French demand can have a major impact on prices in Switzerland, especially in hours with very high loads.
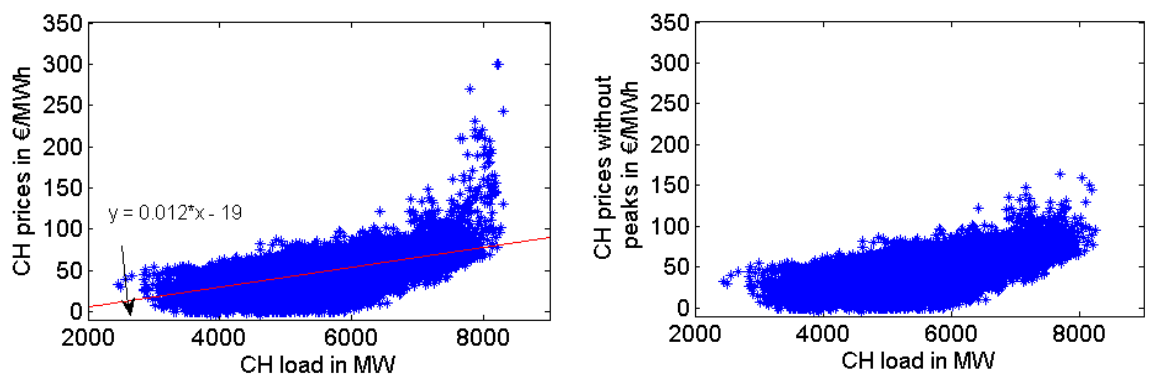

Figure 3: Scatter diagram of the Swiss electricity price and the Swiss load as well as scatter diagram without prices at the same hour with French load greater than 89 GW.

As a result of this preliminary analysis, the study about cross-border drivers of Swiss electricity prices will focus on the relative influence of demand from neighbouring countries in the following, as demand can be also regarded as one of the main drivers for any domestic electricity price [37. Besides, peculiarities of different markets, such as the high RES penetration in Germany or large share of gas power production in Italy, will be captured in this analysis. Therefore, we formulate two modeling approaches that consider demand/load of the neighbouring countries, wind and PV power generation of Germany and gas prices as price drivers. Finally, the correlation analysis of the French load shows that the influence of the drivers on electricity prices can vary among the different seasons of the year. Hence, it is worth analyzing the influence of the cross-border drivers separately for the winter and summer season as mentioned in Section 1 .

\section{Modeling cross-border effects on Swiss electricity prices}

The goal of the following modeling approach, especially the selection of variables, is to investigate significant cross-border divers of Swiss electricity prices. For this purpose, we develop two different approaches, a multiple linear regression combined with hypothesis testing for statistical inference, and a 
Nash-Cournot equilibrium model for a bottom-up view on the relations between electricity markets.

\subsection{Econometric model considering cross-border fundamentals}

As was discussed above, the focus of this study is the effects that the electrical load as a proxy for the electricity demand from surrounding countries, gas prices and renewable energy production from Germany have onto the electricity price in Switzerland. We assume that we can neglect a real-time price elasticity of demand in Switzerland and the neighboring countries as studies show that this is hardly observable in empirical data [38. This puts us into the position that we can employ simple econometric methods to measure the different seasonal effects of price drivers on the Swiss electricity price.

In this section, we will discuss stationarity, autocorrelation, linearity of the relations, and collinearity of the underlying processes and derive a modelling technique that enables us to measure the seasonal differences in effect size of the different fundamental drivers resolved hourly across the day.

During the analysis of the data, we have made the observation that the division of the data set into 24 time series, one for each hour of the day, helps to reduce unwanted effects for a multivariate regression model. On the one hand, the relationships between dependent and independent variables are kept linear. While usually the relationship between load and electricity price is non-linear (depending on the merit-order of power plants), the division into hourly series helps to maintain a load level that corresponds to approximately linear segments of the merit order curve. This is due to the fact that the daily demand curves are relatively similar across different days, reflecting the daily routines of the population and economy. On the other hand, we can analyze the effects in a more detailed manner and differentiate effect sizes in different hours.

The uniformity of patterns of electricity use has further implications on the requirements of regression analysis. The course of the weeks is relatively repetitive, so it is no wonder that we encounter autocorrelation and non-stationary behavior in the time series. In order to be able to analyze the data properly without violating the assumptions of least squares regression, we difference the time series with a lag of 7 days (denoted by $\Delta^{7 d}$ ) as often done in SARIMA modelling [16. This successfully reduces autocorrelation and non-stationarity. However, to handle remaining autocorrelation, especially that between of the same hours of successive days, we introduce a last term to the regression models that considers the values of the day before $\left(\Delta^{7 d}\right.$ price $\left.{ }_{h, d-1}^{C H}\right)$ as a another regressor. Finally, conducting Kwiatkowski-Phillips-Schmidt-Shin (KPSS) tests for all variables for stationarity without trend and lag of $\sqrt{D}$ as proposed by 39 does not reject the null of stationarity for any of the differenced time series.

Collinearity or multicollinearity between the independent variables can inflate the standard errors of least squares estimators and thus make the interpretation of coefficients difficult [40]. A standard measure of collinearity is the Variance Inflation Factor (VIF). Before dividing the data into hourly sub-series and differencing, Swiss load has a VIF of 18.6 given the other independent variables. However, after applying the aforementioned two transformations we encounter a maximum VIF of 6.54 across all variables and seasons (compare the Tables 5 and 6 in the Appendix. This is below the commonly used threshold of a VIF of 10 [40]. This is not to say that collinearity will have no effect onto the findings of this study, as effects can already be studied below this threshold 
40. The coefficients and its signs of the Swiss load that showcases the highest VIFs must be interpreted with collinearity in mind. However, we stress that collinearity is a natural phenomenon that is impossible to avoid 41. Increased standard errors due to collinearity might mean that we falsely cannot reject the null of no effect of a variable (Type II error). However, the results still provide meaningful insights to cross-border price effects.

With regard to the findings and the obtained standard errors we argue that collinearity issues are controlled for.

The above considerations result in the following 24 regression models for each hour of the day:

$$
\begin{aligned}
\Delta^{7 d} \text { price }_{h, d}^{C H}= & c^{h}+b_{1}^{h} \cdot \Delta^{7 d} P V_{h, d}^{D E}+b_{2}^{h} \cdot \Delta^{7 d} \text { wind }_{h, d}^{D E} \\
& +b_{3}^{h} \cdot \Delta^{7 d} \operatorname{load}_{h, d}^{D E+A T}+b_{4}^{h} \cdot \Delta^{7 d} \text { gas }_{d} \\
& +b_{5}^{h} \cdot \Delta^{7 d} \operatorname{load}_{h, d}^{I T}+b_{6}^{h} \cdot \Delta^{7 d} \operatorname{load}_{h, d}^{F R} \\
& +b_{7}^{h} \cdot \operatorname{load}_{h, d}^{C H}+b_{8}^{h} \cdot \Delta^{7 d} \text { price }_{h, d-1}^{C H}+\varepsilon_{d}^{h} \\
& \text { for } 1 \leq h \leq 24 .
\end{aligned}
$$

$1 \leq h \leq 24$ is the hour of the day and $1 \leq d \leq D$ the day between January 1,2015 and the 31st of December 2017. $b_{i}^{h}$ for $1 \leq i \leq 8$ are the regression coefficients, calculated using the least squares estimator. $\Delta^{7 d}$ describes the seven-day seasonal differentiation operator. The German PV feed-in $\Delta^{7 d} P V_{h, t}^{D E}$ only enters the models in the hours between 9 a.m. and 6 p.m., the influence before and after is negligible. As mentioned above, we divide the data into two seasons (spring/summer and fall/winter) to identify seasonal differences in the influence of fundamental price drivers on the Swiss electricity price.

The analysis of residuals reveals low-level heteroscedasticity of the errors in some models. While the estimate of Ordinary Least Squares Estimator (OLS) remains unbiased, the standard errors are affected by the violation of OLS prerequisites. Statistical inference based on the usual standard errors would thus possibly be prone to underestimate standard errors and compromise hypothesis testing. We therefore calculate Newey-West standard errors 42 that account for heteroscedasticity ${ }^{4}$ Table 7 in the Appendix summarizes all coefficient estimates including their (Newey-West) standard errors.

Table 4 summarizes performance indicators for the 24 hours in both seasons. It can be noted that the error measures, root mean square error (RMSE) and mean absolute error (MAE) are generally lower at night and during spring/summer, while $R^{2}$ is lower in fall/winter. Interestingly, the models explain more of the variance during day time as compared to the night. One notable exception is the model of hour 3 in summer. We observe a remarkably low $R^{2}$ during this particular hour, presumably due to a collinearity effect.

The main motivation of this article is the investigation of price drivers with seasonal differences in the effect on electricity prices. In order to statistically evaluate the differences, we test the null of equality of model coefficients for different samples (winter and summer). We calculate the following z-score as

\footnotetext{
${ }^{4}$ In the following, whenever we refer to standard errors, we actually mean heteroscedasticity consistent Newey-West standard errors.
} 
Table 4: Performance indicators for the 24 models

\begin{tabular}{|c|c|c|c|c|c|}
\hline Season & Hour & $R^{2}$ & $\operatorname{adj} R^{2}$ & $\mathrm{RMSE}[€ / \mathrm{MWh}]$ & $\mathrm{MAE}[€ / \mathrm{MWh}]$ \\
\hline \multirow{24}{*}{ Summer } & 1 & 0.49 & 0,49 & 4.20 & 3.11 \\
\hline & 2 & 0.51 & 0.50 & 4.13 & 3.03 \\
\hline & 3 & 0.29 & 0.28 & 5.12 & 3.68 \\
\hline & 4 & 0.63 & 0.62 & 3.75 & 2.73 \\
\hline & 5 & 0.67 & 0.66 & 3.60 & 2.68 \\
\hline & 6 & 0.63 & 0.63 & 3.75 & 2.76 \\
\hline & 7 & 0.56 & 0.55 & 4.43 & 3.21 \\
\hline & 8 & 0.62 & 0.62 & 4.39 & 3.21 \\
\hline & 9 & 0.66 & 0.66 & 4.38 & 3.22 \\
\hline & 10 & 0.65 & 0.64 & 4.48 & 3.30 \\
\hline & 11 & 0.60 & 0.60 & 4.55 & 3.37 \\
\hline & 12 & 0.56 & 0.56 & 4.85 & 3.55 \\
\hline & 13 & 0.52 & 0.51 & 5.02 & 3.66 \\
\hline & 14 & 0.48 & 0.47 & 5.42 & 3.76 \\
\hline & 15 & 0.44 & 0.43 & 6.44 & 3.99 \\
\hline & 16 & 0.44 & 0.43 & 6.54 & 4.11 \\
\hline & 17 & 0.49 & 0.48 & 5.89 & 3.82 \\
\hline & 18 & 0.56 & 0.55 & 4.74 & 3.41 \\
\hline & 19 & 0.62 & 0.62 & 4.12 & 3.04 \\
\hline & 20 & 0.61 & 0.61 & 4.13 & 3.10 \\
\hline & 21 & 0.59 & 0.58 & 4.11 & 3.08 \\
\hline & 22 & 0.57 & 0.56 & 4.01 & 3.00 \\
\hline & 23 & 0.54 & 0.53 & 3.91 & 2.95 \\
\hline & 24 & 0.50 & 0.49 & 4.03 & 3.02 \\
\hline \multirow{24}{*}{ Winter } & 1 & 0.59 & 0.58 & 5.50 & 4.06 \\
\hline & 2 & 0.57 & 0.56 & 5.56 & 4.17 \\
\hline & 3 & 0.51 & 0.50 & 5.82 & 4.22 \\
\hline & 4 & 0.50 & 0.49 & 5.93 & 4.30 \\
\hline & 5 & 0.51 & 0.51 & 5.91 & 4.28 \\
\hline & 6 & 0.49 & 0.48 & 6.35 & 4.57 \\
\hline & 7 & 0.58 & 0.57 & 6.86 & 4.87 \\
\hline & 8 & 0.62 & 0.61 & 8.45 & 5.68 \\
\hline & 9 & 0.57 & 0.57 & 10.30 & 6.61 \\
\hline & 10 & 0.60 & 0.60 & 9.35 & 6.18 \\
\hline & 11 & 0.63 & 0.62 & 8.65 & 5.93 \\
\hline & 12 & 0.64 & 0.63 & 7.98 & 5.58 \\
\hline & 13 & 0.65 & 0.64 & 7.05 & 4.91 \\
\hline & 14 & 0.65 & 0.64 & 7.10 & 5.03 \\
\hline & 15 & 0.64 & 0.64 & 7.36 & 5.25 \\
\hline & 16 & 0.62 & 0.61 & 7.91 & 5.53 \\
\hline & 17 & 0.62 & 0.61 & 7.88 & 5.60 \\
\hline & 18 & 0.58 & 0.57 & 9.35 & 6.47 \\
\hline & 19 & 0.58 & 0.58 & 10.08 & 6.83 \\
\hline & 20 & 0.60 & 0.60 & 7.82 & 5.47 \\
\hline & 21 & 0.64 & 0.64 & 5.87 & 4.25 \\
\hline & 22 & 0.63 & 0.63 & 5.48 & 3.99 \\
\hline & 23 & 0.65 & 0.64 & 5.23 & 3.86 \\
\hline & 24 & 0.63 & 0.63 & 5.52 & 4.18 \\
\hline
\end{tabular}


proposed in the literature 43, 44. Suppose $b_{j}$ and $\hat{b}_{j}$ are coefficients for the same explanatory variable on different samples with standard errors $s e_{j}$ and $\hat{s e}{ }_{j}$. Then we obtain the z-statistic by

$$
Z_{j}=\frac{b_{j}-\hat{b}_{j}}{\sqrt{s e_{j}^{2}+\hat{s e}_{j}^{2}}}
$$

which follows a standard normal distribution. Based on the z-statistic we can judge on the significance of a seasonal effect. The detailed findings are presented in Table 9 in the Appendix

The proposed modelling technique and inference procedure enables us to a detailed investigation of the seasonal effects of cross-border drivers of an electricity price. However, the high temporal resolution of the models comes with a price. In order to assess effects and seasonal differences, $24 \times 2 \times 7$ coefficients have to be tested and compared. To be able to interpret the results of this study, a graphical evaluation tool was developed in order to sum up all information in a limited number of graphs (see, for instance, Figure 4). A detailed description and interpretation aid is given in Section 5.1 .

\subsection{Nash-Cournot model for the electricity market}

The Nash-Cournot model used in this study is the crossBorder Electricity Market model (BEM) 45. The BEM model can represent either a NashCournot game or a social-welfare maximization problem of the electricity markets. In the game-theoretic setup an open-loop formulation is followed [8, in which the market players make their capacity expansion and operating decisions simultaneously to maximize their net profit. In this setup, the Transmission System Operator (TSO) is a price-taker that re-shuffles the electricity quantities produced and demanded to clear the market by solving a DC power flow model with implicit auction ${ }^{5}$ A detailed mathematical description of the model is given in [45] and in the appendix, but we give a short description of the main features of the model below:

$$
\begin{gathered}
\max _{x_{n i j}, q_{n i j h}, q_{n i j h}^{\mathrm{i}}, w_{n i j h}^{\mathrm{o}} \in \mathbb{R}^{+}} p_{n l} \sum_{j} q_{n i j h}-\sum_{j}\left(\tilde{c}_{n i j} x_{n i j}+c_{n i j h}\left(q_{n i j h}+q_{n i j h}^{s}\right)\right) \\
x_{n i j}^{0}+x_{n i j} \leq x_{n i j}^{\max } \\
G_{i}\left(\boldsymbol{Q}_{\boldsymbol{i}}, \boldsymbol{X}_{\boldsymbol{i}} ; \boldsymbol{X}_{\boldsymbol{i}}^{\mathbf{0}}, \boldsymbol{B}_{\boldsymbol{i}}\right) \leq \boldsymbol{b}_{\boldsymbol{i}} \\
H_{i}\left(\boldsymbol{Q}_{\boldsymbol{i}}, \boldsymbol{X}_{\boldsymbol{i}}, \boldsymbol{W}_{\boldsymbol{i}}^{\mathrm{o}} ; \boldsymbol{X}_{\boldsymbol{i}}^{\mathbf{0}}, \boldsymbol{Z}_{\boldsymbol{i}}\right) \leq \boldsymbol{z}_{\boldsymbol{i}} \\
s_{n i j h}=s_{n i j(h-1)}-q_{n i j h} / e_{n i j}+e_{n i j}^{s} q_{n i j h}^{s}+u_{n i j h}^{\text {inflow }}
\end{gathered}
$$

\footnotetext{
${ }^{5}$ The BEM model is written in the GAMS algebraic language [4], and it is solved as a mixed complementarity problem.
} 


$$
H_{i}\left(\boldsymbol{Q}_{i}, \boldsymbol{Q}_{i}^{s}, \boldsymbol{X}_{\boldsymbol{i}}, \boldsymbol{S}_{\boldsymbol{i}} ; \boldsymbol{X}_{\boldsymbol{i}}^{\mathbf{0}}, \boldsymbol{K}_{\boldsymbol{i}}\right) \leq \boldsymbol{k}_{\boldsymbol{i}}
$$

Each player $i$ optimizes the net profit, defined as revenue from electricity sales minus operating and fuel costs, as well as maintenance and capital costs (Eq. (3)); the sum of operating and fuel costs per unit of power produced is denoted by $c_{n i j h}$ in demand node $n$, for player $i$, technology $j$, and hour $h$; the capital cost per capacity is $\tilde{c}_{n i j}$. The decision variables for each player are the quantities $q_{n i j h}$ produced by a plant $j$ located at a node $n$ during the hour $h$, the quantities $q_{n i j h}^{\mathrm{s}}$ entered in a storage plant $j$, the investment capacity $x_{n i j}$ in each plant $j$ at node $n$ and the offline capacity $w_{n i j h}^{\mathrm{o}}$ of each plant $j$ at hour $l$. The players take their operating and dispatching decisions across 96 typical hours (four seasons with one typical day per season with hourly resolution). A continuous relaxation of the unit commitment problem is implemented (see [4]). The equation (4) corresponds to the maximum capacity constraint. The constraints (5) represent capacity-production relationships, such as minimum and maximum production levels due to restrictions in the utilization of the available capacity. The set of constraints (6) represent online capacity constraints, such as minimum stable operating levels, minimum online and offline times, part-load operation efficiency losses, ramping rates and also implement the unit dispatching logic. Electricity storage systems, e.g. batteries and hydrostorage, are subject to energy buffer dynamics as shown in equation (7), where $s_{n i j h}$ denotes charged volume in node $n$, for player $i$, storage technology $j$ and hour $h$, and with a distinct representation of efficiency for charging and discharging, $e$ and $e^{s}$, together with water inflow levels $u_{n i j h}^{\text {inflow }}$. The set of constraints 8 describe the charging and discharging power rating, maximum depth of discharge, and utilization constraints of the storage power plants.

The clearing of the market, i.e. finding the price $p_{n h}$ and demand $d_{n h}$ at the equilibrium point, is done by the TSO. The TSO shuffles the power between the nodes by deciding on the imports $a_{n h}$ in each node $n$ and hour $h$, under the transmission constraints represented by the power distribution matrix $\tilde{p}_{n k}$ and the line capacity $t_{k}^{\max }$ for each node $n$ and transmission line $k$. The problem of the TSO is as follows:

$$
\begin{gathered}
\max _{a_{n h}} \sum_{n, h} p_{n h} a_{n h} \\
\sum_{n=1}^{N} a_{n h}=0 \\
-t_{k}^{\max } \leq \sum_{n=1}^{N} \tilde{p}_{n k} a_{n h} \leq t_{k}^{\max } \\
d_{n h}=\sum_{i, j=1}^{I, J}\left(q_{n i j h}-q_{n i j h}^{s}\right)+a_{n h}
\end{gathered}
$$

In the above formulation, the TSO clears the market (equation (12) by maximising its profit (equation (9)), by avoiding arbitrage (equation (10)) and by respecting the transmission constraints (equation (11)).

The BEM model includes an intrinsic "estimation" mode, in which the historical market volumes and electricity generation are given as an input and 
the calibration of the model is performed on the conduct parameter, such as to reproduce the historical prices. The estimation of the conduct parameter within the same framework ensures consistency between the model calibration and the model results, which is not guaranteed when the deviation between the market prices and the marginal costs is estimated with techniques external to the modelling framework (e.g. econometric analysis). For the estimation of the parameter we use the 2015/6 electricity market data (prices, volumes, generation). Once the conduct parameter is found from the calibration, we keep it constant in the future as we assume that the day-ahead market will have the same relevance in the future response of the market to scarcity situation as of today. The calibration of BEM is discussed in detail in [45].

\section{Drivers of Swiss electricity prices}

\subsection{Results of the econometric model}

The econometric models serve to analyze the influence of different predictors over the course of the day and seasons. Based on the regression model for each hour of the day and for the respective season, the coefficients of the different independent variables are analysed in the following serving as a basis for the interpretation of the influence of each price driver.

We develop a set of graphs in order to interpret the coefficient estimate results of the 48 models. While this is rather unusual in econometric analysis, we find that the procedure well serves the purposes of firstly interpreting the results, and secondly to present the findings concisely. We present eight graphs, one for each explanatory variable. Each graph covers the development of the coefficient estimates during the two seasons across a day (detailed in Appendix in Table 7). The coefficients are interpreted as the rate of change of the conditional mean of the Swiss electricity price with respect to a change in the depicted independent variable. Both seasons are depicted as lines for better readability only. One word of caution: estimates in two consecutive hours are not necessarily significantly different. Only certain peak hours witness a significant difference in effects to other hours on the same day. The confidence interval $(\alpha=0.05)$ is depicted as translucent area coloured according to the line colour of the coefficient it belongs to. Filled markers in both time series indicate a significant difference between the two seasons, according to the testing procedure described in Section 4.1 with detailed results in Appendix in Table 9.

In some hours, coefficients display a contrary sign than the expected one. This occurs, however, only for coefficients that cannot be confirmed to be significant.

As already observed, the similarities of the electricity prices of neighbouring countries are different in both seasons. The comparison of the coefficients in the different periods thus allows conclusions to be drawn about the factors that explain the differences between summer and winter.

Differences of effects between the seasons become clear scrutinizing the values of the regression coefficients by season. Although the significance intervals of hourly coefficients partly overlap for the different seasons in case of the gas price, in the winter the effect of gas prices seem to be in general larger than in the summer. However, this result has to be taken with caution as the statistical test on significance in differences cannot reject the null hypothesis. Regarding 
the Italian load the findings are much clearer: it proves to be more influential in winter, while its effect in summer is significantly lower (see Figure 4).
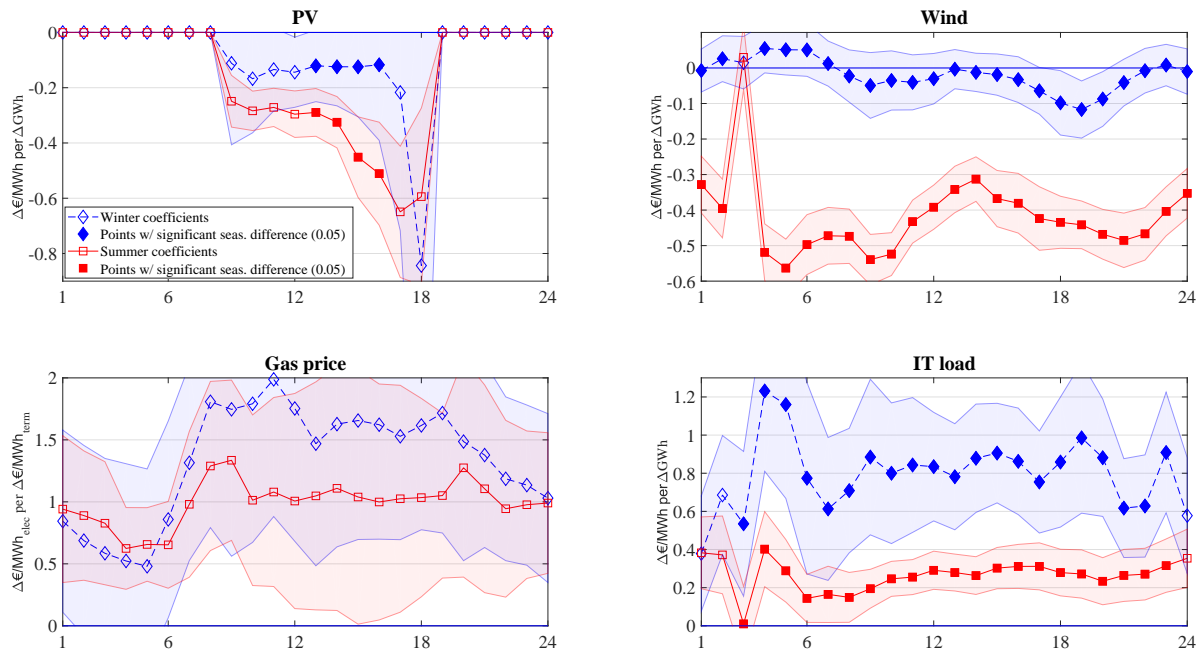

Figure 4: Influence of the different cross-border drivers of Swiss electricity prices. The influence of each driver is derived from the coefficient estimates based on OLS [EUR/MWh per EUR price difference or per additional GW load] in summer (red line) and winter (blue line). Filled markers in both time series indicate a significant difference between the two seasons.

Both trends coincide with the earlier observation that Swiss prices approach Italian prices in winter. Gas prices and the load of the Italian electricity system can be interpreted in the model as representing the Italian electricity price, as we the Italian electricity system mainly relies on gas power plants and these technology is mostly the price-setting one in the Italian energy market. However, since gas power plants are not only operated in Italy, this effect cannot solely be attributed to the Italian market.

The effect of the gas prices shows a further interesting characteristic: In the morning and evening hours, in which the electricity demand is usually the highest, the influence is particularly strong. This is in line with the theory of merit order pricing, according to which power plants with higher marginal costs are used primarily at times when there is a high demand and therefore high prices.

For the German wind and solar power feed-in, Figure 4 reveals a high influence in the summer, whereas in winter no significant influence on Swiss electricity prices can be identified. This is also in line with previous observations that the Swiss electricity price follows the German electricity price much more closely in the summer. Consequently, feed in of power from fluctuating RES in Germany in the summer has a much greater effect in Switzerland as well.

The negative impact of both wind and solar feed-in can be explained by the way in which electricity from RES is marketed. Due to the negligibly low marginal costs and the promotion of RES, they often come into the market at any price and thus lower the price. Although the coefficients show the expected behaviour, caution is required when interpreting them. Since the solar feed-in follows the same pattern in all countries, it is conceivable that the coefficients not only indicate the influence of the German feed-in, but rather make use of the 
overall influence of the PV feed-in. Further methodological developments, e.g. towards partial regression, are necessary if the influences are to be delimited sharply by country.

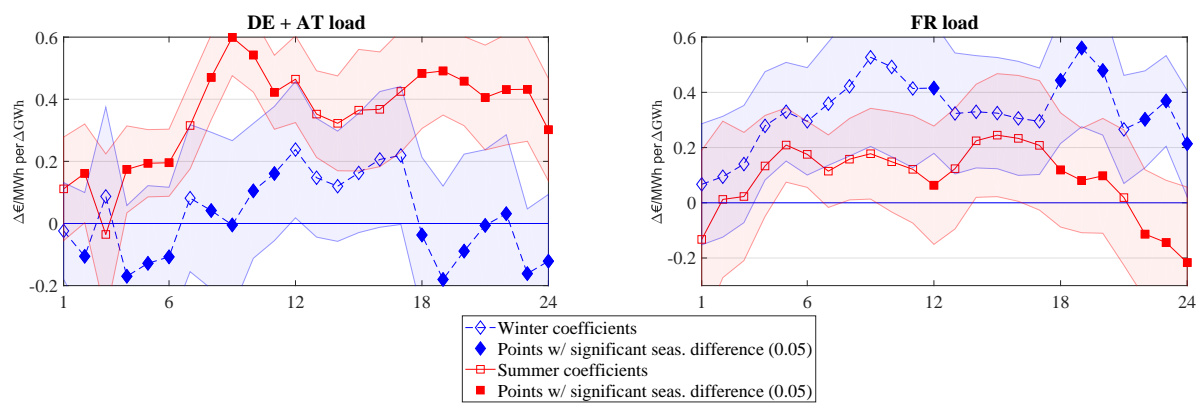

Figure 5: Influence of the German (left) and French load (right) on Swiss electricity prices [EUR/MWh per additional GW] load in summer (red line) and winter (blue line).

Regarding the influence of the different load variables, different results could be derived. While the German load has significant impact in the summer, but not in winter, the influence of the French load is reversed: It is hardly significant in the summer, but has a strong effect in the winter. This might result from the higher French electricity demand for heating in the winter, as the share of demand from electric heaters is higher, if compared to Germany. Both load factors show a similar pattern over the day, with small or even insignificant influence in the night hours when the demand for electricity is the lowest, whereas the highest influence is in the late afternoon, when also the electricity demand peaks (see Figure 5).

Compared to the German or French load, the $\mathrm{CH}$ load has indeed the highest coefficients, however, according to their standard error the Swiss load is hardly significant in any hour of the day, neither in the summer nor in the winter (see Figure 6). This may cohere with the autoregressive component that may also cover some of the autocorrelation of the $\mathrm{CH}$ load factor, but it is more likely that the significance of Swiss load is captured by the loads of the neighbouring markets. Collinearity cannot be ruled out according to the VIFs described above. Hence, it is likely that the domestic load combined with the neighbouring loads play an important role for the $\mathrm{CH}$ electricity prices.

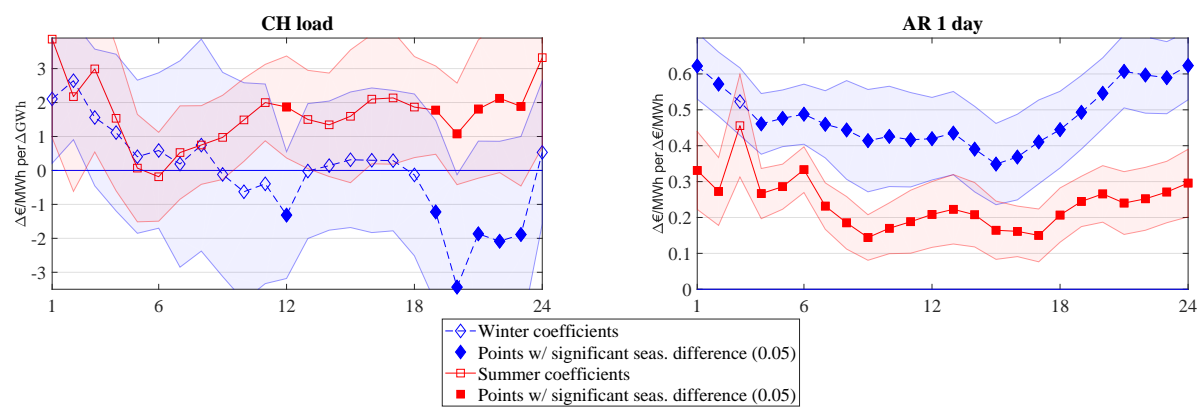

Figure 6: Influence of the Swiss load [EUR/MWh per additional GW] and of the autoregressive term in summer (red line) and winter (blue line). 
Finally, it is worth mentioning that these regression analyses have been carried out without explicit consideration of exchange flows between Switzerland and its neighbouring countries. The rationale for this approach was to analyse the relationship between Swiss prices and the primary fundamental drivers of the neighbouring countries, such as demand and RES power generation. Hence, a regression model that covers fundamental drivers of the neighbours and that estimated with historical data, implicitly integrates the exchange constraints. However, to further investigate if there is an effect of available cross-border transfer capacities, we have generated dummy variables that are set to "1" if cross-border transfer capacities were not saturated, which means scheduled exchange flows between $\mathrm{CH}$ and its neighbours were smaller than the transfer capacities in the analysed time-period (2015 to 2017). For the hours of the time period, in which the transfer capacities were fully utilized, the dummy variable is set to "0". As Switzerland was connected to three market zones (FR, IT, $\mathrm{DE} / \mathrm{AT} / \mathrm{LU}$ ), we have generated six dummy variables including the ones for the reverse direction. These dummy variables are added to the original regression models after calculating their 7day-differences. However, the results of these extended regression models hardly differ from the original models, as almost all coefficients of the dummy variables are not statistically significant. Statistical significance could be noticed only for a few hours of the day in case of the coefficient of the dummy variable that indicates whether the connection line from Switzerland to France is fully utilized or not (Figure 9. Appendix). A small difference can be also noted for the coefficient of the French load, whose effect is slightly reduced in some hours in the extended regression model compared to the original effect displayed in Figure 5. These results make sense intuitively, given that interconnectors between France and Switzerland are saturated regularly, while other interconnectors are congested less frequently (Table 8, Appendix). Beside this, there are no remarkable changes, which counts also for the $R^{2}$ of the extended models that improves by 0.01 on average. The results for the coefficients of the extended regression models are reported in the supplementary materials as Excel-file.

\subsection{Cross-border effects determined fundamental Nash-Cournot model}

The influence of the cross-border drivers on Swiss electricity prices determined with the help of the econometric model are cross-checked using a NashCournot equilibrium model, the so-called BEM model. For this purpose, the power plant fleet of 2015/6 is given as input to the BEM model, and several sensitivity analyses are performed with different levels of the same drivers analysed above (i.e. gas prices, solar and wind power in Germany, and electricity load in Switzerland and neighbouring countries). For each driver, the sensitivity runs are over the range of one standard deviation from its mean value. That means that the input values of the analysed driver are changed from the original values to the level by adding or subtracting one standard deviation. This sensitivity runs allows us to benchmark the resulting Swiss electricity price with the (model estimated) prices of $2015 / 6$ that are calculated with the original values of the price drivers for specific hours and type days. More detailed, the price impact of each price driver is calculated as the difference of the Swiss prices originating from the benchmark run and the sensitivity run standardized per unit of the underlying driver. 
Because of the different time granularity of the fundamental BEM model with respect to the econometric modeling, we are not able to compare the hourly effects in a sensitive manner and compare, therefore, for each driver the aggregated effect over seasons and load-periods.

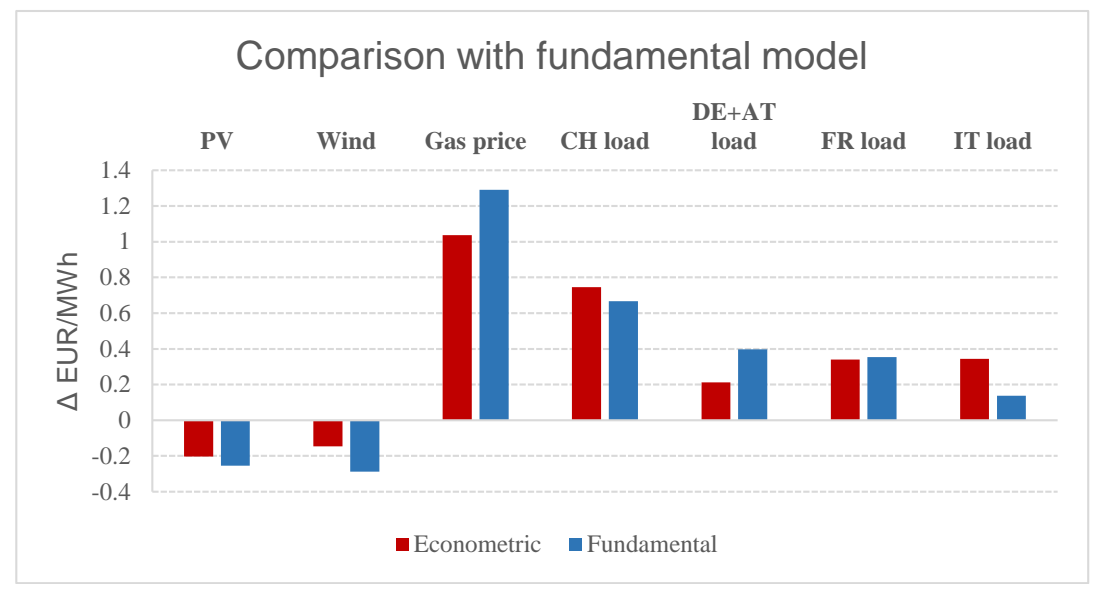

Figure 7: Comparison of the influence factors between the econometric and the fundamental model

Figure 7 shows the influence of the gas price, solar and wind production in Germany and the loads on the Swiss electricity prices for the years 2015 and 2016. As also obtained in Section 5.1, the gas price is determined again to be the most influential driver for the Swiss electricity price. This finding is similar to that found also in other literature (see 32$]^{6}$ and is mainly attributable to the fact that the Swiss electricity price is defined to a large extent by the cross-border trade (see also Fig. 5 where it shows that the impact the nondomestic loads can be also very large in specific hours) and to the fact that gas technologies are price-setting technologies in most of the neighbouring countries (see also [45, 48, 7, 34]).

Similarly to the results obtained in Sec. 5.1, the electricity production from both the wind and solar power in Germany have negative effects on the Swiss price. Although a higher absolute value of the effect is assessed by the fundamental BEM model than the one of the econometric model, the overall effect of the German renewables on the price seem to be lower compared to the other price factors. However, these small values have to be interpreted with caution, as the effect is illustrated as the relative effect, i.e. per GW wind or solar power production. That means that at times with several dozen GW renewable power generation in Germany, the decrease of $\mathrm{CH}$ prices can reach many EUR/MWh.

Both, the German and French loads, have a significant influence, especially compared to the Italian load. The difference in influence is driven by the role of the (small) Swiss region as an exporter and importer with respect to the

\footnotetext{
${ }^{6}$ Frauendorfer et al. (2018) compare the impact of several fuel prices (gas, oil and coal) in their study and find gas prices as the one with the highest coefficients. However, they look at the evolution of this driver between 2011 and 2016 and find also negative values at the end of this period, while we have found only positive price relations between gas and electricity prices between 2015 and 2017 .
} 
other (large) regions as follows. Switzerland is a net importer of electricity from Germany and France, hence the higher the German and French loads are the more expensive the imported electricity becomes (scarcity of capacity effects) and the higher the Swiss price is. By contrast, the Italian load has according to sensitivity results no significant impact on the Swiss price. This is because Switzerland is not dependent on Italian imports, but it exports electricity to Italy. Since there is an upper limit of how much electricity can be exported from Switzerland to Italy (based on water availability and management constraints, as well as on hydropower and transmission capacities constraints) and the Swiss exports are a small share of the total Italian demand, a change in Italian load above a level does not induce a major change in the Swiss price. In other words, the marginal technology in Switzerland by exporting is not changed, which is mainly hydro or nuclear power, whereas high imports from Germany and France can have a significant merit-order effect in Switzerland by pushing domestic production out of the Swiss market clearing.

\subsection{Discussion of both model findings}

The comparison of the results showed that the BEM model could reproduce the findings of the econometric modeling up to some extent (Figure 7). Additionally to the analysis regarding the BEM findings, other factors contribute to the obtained differences, and we discuss them in the following.

The fundamental BEM model considers Switzerland and the surrounding countries (Austria, France, Germany, Italy); electricity trade with other countries (in a potential fringe region) is not considered. Hence, the influence of critical factors, especially of the domestic load in surrounding countries, is confined to the modeled countries. Particularly Germany has several other countries with considerable cross-border transmission capacity. If the load in Germany is high, then trade with these countries can also possibly alleviate the domestic load increase. Accordingly, the impact of the German load can be higher in the fundamental modelling (Figure 7) than in the econometric model. It can be argued that by not accounting for the trade with the fringe region, and for the flexibility in dispatching that this trade could provide, the impact of the domestic load of a neighboring country to the Swiss price can be overestimated in the $\mathrm{BEM}$ model, as it is in the case between $\mathrm{CH}$ and $\mathrm{DE}$ in the figure. Likewise, the neglect of electricity trading with other surrounding countries in Germany, which are not explicitly modelled in BEM, explains the higher impact of German wind and PV electricity generation onto the Swiss market in the BEM model. In situations with high wind generation in Germany, it can be expected that, in reality, this surplus electricity is traded not only with Switzerland but also across other borders that are not considered in BEM. Those additional cross-border exchanges lower the effect of electricity from wind and PV in the econometric model that implicitly includes those effects.

Another source of difference between the BEM and the econometric model lies on the zonal pricing applied to Italy. Currently, Italy is divided into price zones on the producers side, which are active in case of congestion. BEM considers Italy as a single pricing zone, not capturing congestion effects within the country, which can have an impact on prices and cross-border trade with Switzerland. In contrast, the econometric model implicitly considers congestion effects when estimating the effect of the Italian load on the Swiss electricity price. 
On the other hand, non-linear effects can be captured by using BEM, as it comprises the different supply technologies and the corresponding merit-order curves in the different market regions. For example, by increasing the gas price, generation from gas considerably decreases both in Italy and in Germany, such that France becomes the only relevant net exporter among the five regions, which considerably increases prices in Switzerland, especially in the winter. In the example of the sensitivity of an increase in Italian load, Switzerland can export to Italy only to a certain extent because of the non-linear factor of transmission line capacity. Hence, price increases are limited. Another limiting factor is that Switzerland is an important hub for electricity transfers from Germany to Italy [49. This effect is pronounced in the sensitivity modelling (when only the Italian load is varied), such that large parts of the increase are covered by transits from Germany, which keeps price influence relatively low compared with the purely econometric modelling.

The endogenous and explicit representation of trade between Switzerland and neighboring countries in BEM is an important contributor to the observed differences between the two approaches, as the trade is not explicitly accounted in the econometric model. When there is market separation due to network congestion or when markets are oligopolistic (both effects are fundamental design features of BEM), then there could be multiple marginal units that are not operating at their full capacity and thus affect prices [50]. In the context of BEM, this is translated to a price markup imposed by congestion, market power or both congestion and market power, and it is endogenous to the model (see also the extensive discussion of the properties of Nash-Cournot models with transmission constraints in [51]). Thus, BEM can produce higher price impacts compared to the econometric model (which does not explicitly consider such effects), especially with regard to fuel prices and resource availability combined with the implicit congestion pricing followed in BEM 51, because these are drivers for exercising market power in the oligopolistic setup of BEM.

However, despite the differences in the order of magnitude in the comparative results shown in (Figure 7), the direction of the impact is the same in both models. Moreover, the observed differences in the impacts are in the most cases small, compared to the absolute magnitude of the impact, with the exception of Italy for reasons discussed above. Thus, in general, it can be stated that both models assess similar effects of the cross-border drivers and that besides the Swiss load, these drivers play an essential role for the price formation in the smaller market area of Switzerland. The example of Switzerland shows that in tightly connected market areas, smaller countries become, to some extent, price-takers and their electricity prices significantly follow the prices of their larger neighbours. The above considerations show that the comparative discussion of both models is very fruitful to gain a deeper understanding of the effects measured by the econometric model. The modelling assumptions of the oligopolistic model BEM, and its underlying mathematical framework, include a perspective on underlying market mechanisms that enrich our empirical findings. The strength of the BEM model is the representation of a detailed and traceable causality chain regarding the operation of the electricity market and its impact on the Swiss electricity prices. The strength of the econometric model is that it can quickly identify those factors that drive the operation of the market and have the most significant impact on the Swiss electricity prices. Thus, the joint application of BEM and econometrics constitutes a robust approach to 
identify market drivers and trace their interaction with respect to their impact on the Swiss electricity prices.

\section{Critical Reflection}

The applied econometric model uses different cross-border fundamentals, but not the cross-border flows themselves as an explanatory variable. So one can legitimately see this as a shortcoming of the modeling approach, as there is a clear relationship between cross-border (import/export) flows and electricity prices. For statistical reasons, however, this relationship cannot accurately be included in the econometric modeling exercise. We will discuss the theoretical problems in some detail in the following.

The causality between electricity prices and import/export flows starts with price differences in two market zones/countries. The same applies to other goods and commodities that are traded across regions. According to economics and electricity market literature (see [52, [53]), an existing price difference between two market zones causes electricity exports from the low price zone to the high price zone and induces welfare increases. As the interconnector capacities between two market areas are limited, electricity is exported until the transfer capacities are fully utilized, or the prices in both zones are equalized. The exports, in turn, lead to price adjustments in both zones, which means that the prices in the exporting zone increase, while they decrease in the importing zone. Therefore, it can be noted that electricity prices and import/export flows are simultaneously occurring phenomena, where both variables are influencing each other. We can also describe this relationship as a causal loop or bidirectional influence. However, the regression model is only able to describe unidirectional relationships, which means regressors are influencing the dependent variable. Considering only one direction of the bidirectional relationship in a regression model would lead to the so-called simultaneity bias (see [54]). Hence, we refrained from including cross-border flows in our model. We instead consider indirect fundamental cross-border drivers, such as demand and RES production, in the econometric model. However, the general equilibrium model allows us to capture the simultaneous cross-influence of import/exports and electricity prices. We, therefore, use the BEM model results to double-check and validate the results of the econometric model and to support them by demonstrating that there are - to a certain extent - similarities in the results of both models with regard to most of the analyzed cross-border drivers.

Besides, the goal of our study is to analyze how fundamental drivers, such as demand and RES power generation, that originate from one country affect the prices of a neighbouring country using Swiss electricity prices as a case study. As the demand situation in the neighbouring market areas and RES generation in Germany have large influence on the export/import flows, the addition of these flows to the econometric model would distort the beta coefficients of the original drivers (load and RES generation) making them non-interpretable (as it was the case in initial model tests with export/import flows). Therefore, a regression model for prices works either with the fundamental drivers from the neighbouring countries or the export/import flows, but not both. To avoid collinearity between the fundamental drivers and the flows and to detect directly the influence of the fundamentals, such as demand/load and RES generation, instead of export/import flows, we have decided for a regression model without 
import/export flows. Our finding in this regard is also that analyzing crossborder drivers, one can use either export/import flows or the fundamentals of the neighbouring countries as regressors, but not both, as there is a strong inter-dependency between both factors.

Beside the cross-border flows, the transfer capacities (TC) to the neighbouring countries have an impact on electricity prices, as their upper limit stops price convergence between neighbouring market areas in specific hours. This means the transfer capacities become price influencing if especially the electricity flows between two market zones reach the TCs. The analysis of the day-ahead forecasts for TCs, published at the ENSTO-E transparency platform [55], show that the commercial flows indeed reach the TCs quite often for some interconnections (e.g. for the interconnection GER/AT to $\mathrm{CH}$ in $25 \%$ of the hours of a year). However, a further analyses based on scatter plots (see Figure 8) and correlation analyses of the hourly changing TCs indicate that the influence of the differences of TCs on the Swiss price differences are negligibly small, although the TCs are often completely used. For instance, the $R^{2}$ between price changes $\Delta^{7 d} p_{h}^{C H}$ and the changes of the TCs $\Delta^{7 d} T C_{h}^{G E R / A T-C H}$ equals to only $1.5 \%$. Because of this negligibly small linear relationship, we have not included TCs to the econometric model. We could have implemented interaction terms to capture non-linear effects and especially interactions between between TCs and other explanatory variables. However, in this case it would be difficult to interpret the results of the regression model. But we have used the transfer capacities in the equilibrium model. The small deviations between the results of the equilibrium and the econometric model illustrates that the econometric model is still reliable for the detailed analysis of intra-year (e.g. seasonal) influences of cross-border drivers, although TCs themselves are not part of the explanatory variables.

Finally, it is worth mentioning that the analysed market area (CH-FR-IT$\mathrm{DE} / \mathrm{AT}$ ) is only a part of the whole European market area. However, with regard to the influencing factors of $\mathrm{CH}$ prices, which is in the focus of this paper, the investigated area is the most relevant one. The influence of the remaining part of Europe has an indirect and smaller effect on Swiss prices, only via imports/exports to the neighboring countries changing the residual demand of these countries. However, as the imports into the neighbouring countries equal to only a small percentage of the overall load/demand curve in most of the time (see Appendix Table 10 and Table 11), their contribution to the Swiss price effect can be neglected and the load curves of the neighbouring countries can be used as a good approximate for the demand of the interconnected areas. For this reason and to derive reasonable results for the cross-border drivers of the neighbouring countries, we do not consider the factors originating from non-neighbouring countries.

\section{Conclusions}

As neighbouring electricity markets are increasingly coupled with each other, cross-border impacts of one market characteristics on prices at other markets become increasingly relevant. For this reason, this investigation analyses the hypothesis that factors affecting the electricity prices of one country also influence the development of the electricity price in the neighbouring countries. 
Based on the example of the Swiss electricity market, the effect of cross-border drivers become more significant, as Switzerland is well-connected to electricity networks of large neighbouring electricity markets, which in turn allow high quantities of cross-border trading.

Based on model results, first of all, we could demonstrate that the applied approaches, multiple regression models and Nash-Cournot equilibrium models, are very effective to analyze cross-border price drivers. The error terms of the model classes are quite low and comparable to the errors of price models found in the literature.

The analysis of these cross-border drivers shows that coupling of markets and large cross-border transmission capacities play a decisive role in explaining domestic electricity prices. Various interrelationships could be demonstrated: It turned out that the Swiss electricity price strongly interacts with the load of the neighbouring energy markets. However, this relationship changes in the different seasons. In spring and summer, there is a strong correlation between the German, French and Swiss electricity prices, while the Swiss electricity price in winter is limited by the French or Italian electricity price. The correlation in the prices reflects the influence of the different load factors.

It can be concluded that the German load affects the Swiss electricity prices more strongly in the summer, although the difference in winter/summer coefficients could not be determined as statistically significant for all hours of the day. The effect of the French load on Swiss electricity prices is rather significant in the evening hours in winter, when it reaches its peak values. In the evening hours in the winter, there is a large demand for electricity caused also by the large number electrical heating devices in France leading to scarcity in supply and higher prices, which then attract more and more exports from Switzerland to France. These exports can in turn drive the prices in Switzerland also into peak areas. Based on these empirical results, it can be concluded that prices of a tightly connected market area can be strongly influenced by the demand in the neighbouring regions and that this influence may change in the case of electricity, which is hardly storable, on an hourly basis.

Besides the influence of the demand/load factors of neighbouring countries, the renewable power production in the bordering markets play an important role for Swiss electricity prices. Although the effect is not that strong as the one of the neighbouring loads, it is still significant for the German wind and solar power production, especially in the summer. The influence of German renewables becomes stronger in the summer, as the demand in neighbouring countries and exports of Swiss electricity producers are less important in this period which makes the effect of German renewables more visible. Furthermore, the renewables, especially solar power plants, during summer produce larger amounts of energy, what leads to surplus or low-cost electricity in Germany which is then transferred to the neighbours. In case of the smaller market area of Switzerland, the RES imports from Germany lead to large reductions in Swiss electricity prices. Hence, it can be stated that the market coupling and tight network connection to the neighbouring countries lead to profits in terms of consumer rent originating from the expansion of renewable energies and to a better distribution of surplus production among neighbouring market areas.

Among the analyzed price drivers, the strongest relative effect could be determined for the gas price by both models, the econometric and the Nash-Cournot model. Although the gas price cannot be assigned to a single country or market 
(natural gas prices throughout Europe are quite at the same level), in this study they can be assigned to Italy or Germany, as the electricity systems of these countries rely on gas power production. Due to the large imports/exports to Germany or Italy, gas prices are also strongly affecting the prices in the Swiss electricity market. However, as there is not much deviation in gas prices during the analyzed time period, in absolute terms, the effect of gas prices can be assessed as a small one. In contrast, the fluctuation of demand in the neighbouring countries and the renewable power production in Germany can reach several or even dozens of GWs, so that the absolute effect of these parameters on Swiss electricity prices is much stronger than the one of gas prices. Therefore, the Swiss energy regulators are advised to monitor the development of the German RES expansion and the increase in demand in the neighbouring countries quite closely to understand the impact of these developments on their domestic market and to adjust own market regulations if necessary in time.

\section{Acknowledgements}

This paper is a part of the work within the following research projects: Project "Impact of different market designs in the CWE market area on electricity prices and on the competitiveness of Swiss hydropower", co-funded by Energy-Economy-Society (EWG) programme, grant SI/501308, of Swiss Federal Office for Energy (SFOE); electricity market research within the Swiss Competence Center of Energy Research - Supply of Electricity (SCCER-SoE), Phase II, co-funded by Innosuisse.

\section{References}

[1] Swissgrid, Grid data, https://www.swissgrid.ch/en/home/oper ation/grid-data.html, 2018.

URL https://www.swissgrid.ch/en/home/operation/grid-data.html

[2] ISE, Electricity generation in germany in 2017, Fraunhofer-Institut für Solare Energiesysteme ISE, Freiburg, Germany, 2018.

URL https://www.ise.fraunhofer.de/content/dam/ise/de/ documents/publications/studies/daten-zuerneuerbaren-energien/ Stromerzeugung_2017.pdf

[3] Réseau de Transport d'Electricité, L'essentiel du bilan électrique 2017, http://bilan-electrique-2017.rte-france.com/, 2018.

URL http://bilan-electrique-2017.rte-france.com/

[4] IEA, Italy - energy system overview, International Energy Agency, 2017. URL https://www .iea.org/media/countries/Italy.pdf

[5] Terna, Annual report 2016, Terna, 2017. URL http: //download.terna.it/terna/0000/0908/12.PDF

[6] C. Pape, S. Hagemann, C. Weber, Are fundamentals enough? explaining price variations in the German day-ahead and intraday power market, Energy Economics 54 (2016) 376-387. doi:10.1016/j.eneco.2015.12.013. 
[7] T. Kallabis, C. Pape, C. Weber, The plunge in german electricity futures prices analysis using a parsimonious fundamental model, Energy Policy 95 (2016) 280-290. doi:10.1016/j.enpol.2016.04.025.

[8] S. A. Gabriel, A. J. Conejo, J. D. Fuller, B. F. Hobbs, C. Ruiz, Complementarity Modeling in Energy Markets, Vol. 180 of International Series in Operations Research \& Management Science, Springer, 2013. doi: 10.1007/978-1-4419-6123-5.

[9] P. D. Klemperer, M. A. Meyer, Supply function equilibria in oligopoly under uncertainty, Econometrica 57 (6) (1989) 1243-1277. doi:10.2307/ 1913707.

[10] B. Willems, I. Rumiantseva, H. Weigt, Cournot versus supply functions: What does the data tell us?, Energy Economics 31 (1) (2009) 38-47. doi: $10.1016 / j$. eneco.2008.08.004.

[11] S. Koschker, D. Möst, Perfect competition vs. strategic behaviour models to derive electricity prices and the influence of renewables on market power, OR Spectrum 38 (3) (2015) 661-686. doi:10.1007/s00291-015-0415-x.

[12] W. Lise, V. Linderhof, O. Kuik, C. Kemfert, R. Östling, T. Heinzow, A game theoretic model of the Northwestern European electricity marketmarket power and the environment, Energy Policy 34 (15) (2006) 21232136. doi:10.1016/j.enpol.2005.03.003

[13] W. Lise, B. F. Hobbs, S. Hers, Market power in the European electricity market - The impacts of dry weather and additional transmission capacity, Energy Policy 36 (4) (2008) 1331-1343. doi:10.1016/j.enpol.2007.12. 012 .

[14] W. Lise, J. Sijm, B. F. Hobbs, The impact of the EU ETS on prices, profits and emissions in the power sector: Simulation results with the COMPETES EU20 model, Environmental and Resource Economics 47 (1) (2010) 23-44. doi:10.1007/s10640-010-9362-9.

[15] J. Lagarto, J. A. Sousa, A. Martins, P. Ferrao, Market power analysis in the Iberian electricity market using a conjectural variations model, Energy 76 (2014) 292-305. doi:10.1016/j.energy.2014.08.014.

[16] R. Weron, Electricity price forecasting: A review of the state-of-the-art with a look into the future, International Journal of Forecasting 30 (4) (2014) 1030-1081. doi:10.1016/j.ijforecast.2014.08.008

[17] A. Kian, A. Keyhani, Stochastic price modeling of electricity in deregulated energy markets, in: Proceedings of the 34th Annual Hawaii International Conference on System Sciences, 2001. doi:10.1109/HICSS.2001.926292.

[18] G. Aneiros, J. Vilar, P. Raa, Short-term forecast of daily curves of electricity demand and price, International Journal of Electrical Power and Energy Systems 80 (2016) 96 - 108. doi:https: //doi.org/10.1016/j.ijepes.2016.01.034.

URL http://www.sciencedirect.com/science/article/pii/ S0142061516000466 
[19] A. Bublitz, D. Keles, W. Fichtner, An analysis of the decline of electricity spot prices in europe: Who is to blame?, Energy Policy 107 (2017) 323 336. doi:http://dx.doi.org/10.1016/j.enpol.2017.04.034.

[20] J. Contreras, R. Espinola, F. J. Nogales, A. J. Conejo, Arima models to predict next-day electricity prices, IEEE Transactions on Power Systems 18 (3) (2003) 1014-1020. doi:10.1109/TPWRS.2002.804943.

[21] A. J. Conejo, J. Contreras, R. Espínola, M. A. Plazas, Forecasting electricity prices for a day-ahead pool-based electric energy market, International Journal of Forecasting 21 (3) (2005) 435-462. doi:10.1016/j.ijforecast.2004.12.005.

URL http://www.sciencedirect.com/science/article/pii/ S0169207004001311

[22] K. Maciejowska, Fundamental and speculative shocks, what drives electricity prices?, in: 11th International Conference on the European Energy Market (EEM14), 2014, pp. 1-5. doi:10.1109/EEM.2014.6861289

[23] S. Cl, A. Cataldi, P. Zoppoli, The merit-order effect in the italian power market: The impact of solar and wind generation on national wholesale electricity prices, Energy Policy 77 (2015) $79-88$. doi:https://doi.org/10.1016/j.enpol.2014.11.038.

URL http://www.sciencedirect.com/science/article/pii/ S0301421514006661

[24] E. Denny, A. Tuohy, P. Meibom, A. Keane, D. Flynn, A. Mullane, M. OMalley, The impact of increased interconnection on electricity systems with large penetrations of wind generation: A case study of ireland and great britain, Energy Policy 38 (11) (2010) 6946 6954, energy Efficiency Policies and Strategies with regular papers. doi:https://doi.org/10.1016/j.enpol.2010.07.011.

URL http://www.sciencedirect.com/science/article/pii/ S0301421510005409

[25] D. C. S. W. Derek Bunn, Arne Andresen, Analysis and Forecasting of Electricty Price Risks with Quantile Factor Models, The Energy Journal 0 (Number 1).

URL https://ideas.repec.org/a/aen/journl/ej37-1-bunn.html

[26] L. Parisio, B. Bosco, Electricity prices and cross-border trade: Volume and strategy effects, Energy Economics 30 (4) (2008) 1760-1775. doi: $10.1016 / j$.eneco.2008.01.002.

[27] G. Zachmann, Electricity wholesale market prices in europe: Convergence?, Energy Economics 30 (4) (2008) 1659-1671.

URL https://EconPapers.repec.org/RePEc:eee:eneeco:v:30:y: 2008:i:4:p:1659-1671

[28] J. C. Richstein, E. J. Chappin, L. J. de Vries, Cross-border electricity market effects due to price caps in an emission trading system: An agentbased approach, Energy Policy 71 (2014) 139-158. doi:10.1016/j . enpol. 2014.03.037. 
[29] J. Horst Keppler, S. Phan, Y. Le Pen, The impacts of variable renewable production and market coupling on the convergence of french and german electricity prices, The Energy Journal 37 (3). doi:10.5547/01956574.37. 3.jkep

[30] S. Phan, F. Roques, Is the depressive effect of renewables on power prices contagious? A cross border econometric analysis, Cambridge Working Papers in Economics 1527, Faculty of Economics, University of Cambridge (Sep. 2015).

URL https://ideas.repec.org/p/cam/camdae/1527.html

[31] F. Ziel, R. Steinert, Electricity price forecasting using sale and purchase curves: The x-model, Energy Economics 59 (2016) 435-454.

[32] K. Frauendorfer, F. Paraschiv, M. Schürle, Cross-border effects on swiss electricity prices in the light of the energy transition, Energies 11 (9) (2018) 2188. doi:10.3390/en11092188.

[33] R. Kiesel, F. Paraschiv, Econometric analysis of 15-minute intraday electricity prices, Energy Economics 64. doi:10.1016/j.eneco.2017.03.002

[34] M. Everts, C. Huber, E. Blume-Werry, Politics vs markets: how German power prices hit the floor, Journal of World Energy Law Business 9 (2) (2016) 116-123. doi:10.1093/jwelb/jww005.

[35] T. Traber, C. Kemfert, Impacts of the german support for renewable energy on electricity prices, emissions, and firms, The Energy Journal 30 (3). doi : 10.5547/issn0195-6574-ej-vol30-no3-8

[36] C. Graf, D. Wozabal, Measuring competitiveness of the epex spot market for electricity, Energy Policy 62 (2013) 948-958. doi:10.1016/j.enpol. 2013.07.052.

[37] P. Mandal, T. Senjyu, N. Urasaki, T. Funabashi, A. K. Srivastava, A novel approach to forecast electricity price for pjm using neural network and similar days method, IEEE Transactions on Power Systems 22 (4) (2007) 2058-2065. doi:10.1109/TPWRS.2007.907386

[38] M. G. Lijesen, The real-time price elasticity of electricity, Energy Economics 29 (2) (2007) 249-258. doi:10.1016/j.eneco.2006.08.008.

[39] D. Kwiatkowski, P. C. Phillips, P. Schmidt, Y. Shin, Testing the null hypothesis of stationarity against the alternative of a unit root: How sure are we that economic time series have a unit root?, Journal of Econometrics 54 (1) (1992) 159 - 178. doi:https://doi.org/10.1016/0304-4076(92) 90104-Y

[40] J. F. Hair, Multivariate data analysis, 7th Edition, Pearson Prentice Hall, Upper Saddle River, NJ, 2010.

[41] D. N. Gujarati, D. C. Porter, Basic econometrics (ed.), New York: McGrawHiII. 
[42] W. K. Newey, K. D. West, A simple, positive semi-definite, heteroskedasticity and autocorrelation consistent covariance matrix, Econometrica 55 (3) (1987) 703-708.

URL http://www . jstor .org/stable/1913610

[43] C. C. Clogg, E. Petkova, A. Haritou, Statistical Methods for Comparing Regression Coefficients Between Models, American Journal of Sociology 100 (5) (1995) 1261-1293. doi:10.1086/230638.

[44] R. Paternoster, R. Brame, P. Mazerolle, A. Piquero, Using the correct statistical test for the equality of regression coefficients, Criminology 36 (4) (1998) 859-866. doi:10.1111/j.1745-9125.1998.tb01268.x.

[45] E. Panos, M. Densing, K. Schmedders, Oligopolistic capacity expansion with subsequent market-bidding under transmission constraints (OCESM), Tech. rep. (2017).

URL https://www.aramis.admin.ch/Default.aspx?DocumentID= $46075\{\&\}$ Load=true

[46] E. Rosenthal, GAMS - A User's Guide, Tech. rep., Washington, DC, USA (2017).

[47] E. Panos, A. Lehtilä, Dispatching and unit commitment features in TIMES, Tech. rep. (2016).

URL/https://iea-etsap.org/docs/TIMES Dispatching Documentation. pdf

[48] D. Keles, A. Bublitz, F. Zimmermann, M. Genoese, W. Fichtner, Analysis of design options for the electricity market: The german case, Applied Energy 183 (2016) 884-901. doi:10.1016/j.apenergy.2016.08.189.

[49] B. von Kupsch, Technical report on Strategic Grid 2025, Tech. rep., Swissgrid, Laufenburg, Switzerland (2015).

URL https://www.swissgrid.ch/dam/swissgrid/projects/ strategic-grid/sg2025-technical-report-de.pdf

[50] Y. Chen, J. Sijm, B. F. Hobbs, W. Lise, Implications of co2 emissions trading for short-run electricity market outcomes in northwest europe, Journal of Regulatory Economics 34 (3) (2008) 251-281. doi:10.1007/ s11149-008-9069-9

[51] C. Metzler, B. F. Hobbs, J.-S. Pang, Nash-Cournot equilibria in power markets on a linearized DC network with arbitrage: Formulations and properties, Networks and Spatial Economics 3 (2) (2003) 123-150. doi: 10.1023/a:1023907818360

[52] P. Ringler, D. Keles, W. Fichtner, How to benefit from a common european electricity market design, Energy Policy 101 (2017) 629 - 643. doi:10. 1016/j.enpol.2016.11.011.

[53] N. Mankiw, Principles of Microeconomics, Economics Series, Cengage Learning, 2011.

URL https://books .google.de/books?id=BY_VlQYWdpAC 
Table 5: Variance Inflation Factors (VIF) for fall and winter for the specified model

\begin{tabular}{|c|c|c|c|c|c|c|c|}
\hline Hour & Solar & Wind & Gas price & $\mathrm{CH}$ load & DE+AT load & FR load & IT load \\
\hline 1 & & 1,25 & 1,06 & 4,71 & 2,01 & 4,13 & 1,57 \\
\hline 2 & & 1,26 & 1,06 & 4,36 & 2,16 & 3,81 & 1,62 \\
\hline 3 & & 1,26 & 1,06 & 4,12 & 2,12 & 3,64 & 1,65 \\
\hline 4 & & 1,27 & 1,05 & 4,11 & 2,12 & 3,68 & 1,71 \\
\hline 5 & & 1,29 & 1,04 & 3,80 & 2,38 & 3,07 & 1,93 \\
\hline 6 & & 1,24 & 1,03 & 4,77 & 3,00 & 2,96 & 2,73 \\
\hline 7 & & 1,21 & 1,03 & 5,71 & 3,42 & 2,65 & 3,09 \\
\hline 8 & & 1,23 & 1,04 & 6,27 & 3,97 & 2,45 & 2,87 \\
\hline 9 & 1,14 & 1,31 & 1,11 & 6,18 & 4,02 & 2,45 & 2,72 \\
\hline 10 & 1,14 & 1,32 & 1,10 & 5,40 & 3,46 & 2,40 & 2,68 \\
\hline 11 & 1,14 & 1,33 & 1,08 & 4,76 & 3,12 & 2,17 & 2,56 \\
\hline 12 & 1,16 & 1,36 & 1,09 & 4,23 & 2,81 & 1,98 & 2,40 \\
\hline 13 & 1,20 & 1,35 & 1,09 & 3,90 & 2,64 & 2,15 & 2,30 \\
\hline 14 & 1,21 & 1,35 & 1,10 & 4,05 & 2,80 & 2,23 & 2,25 \\
\hline 15 & 1,22 & 1,34 & 1,10 & 3,98 & 2,89 & 2,25 & 2,22 \\
\hline 16 & 1,22 & 1,34 & 1,11 & 3,96 & 2,94 & 2,28 & 2,21 \\
\hline 17 & 1,21 & 1,37 & 1,12 & 4,07 & 2,84 & 2,35 & 2,11 \\
\hline 18 & 1,15 & 1,33 & 1,12 & 4,30 & 2,88 & 2,54 & 2,09 \\
\hline 19 & & 1,27 & 1,11 & 4,79 & 3,12 & 2,75 & 2,27 \\
\hline 20 & & 1,32 & 1,10 & 5,92 & 3,22 & 3,36 & 2,31 \\
\hline 21 & & 1,38 & 1,09 & 6,54 & 3,24 & 3,64 & 2,33 \\
\hline 22 & & 1,42 & 1,10 & 6,00 & 3,05 & 3,60 & 2,19 \\
\hline 23 & & 1,32 & 1,10 & 5,11 & 2,65 & 3,57 & 2,04 \\
\hline 24 & & 1,35 & 1,10 & 5,06 & 2,64 & 4,12 & 1,83 \\
\hline
\end{tabular}

[54] M. J. Greenwood, Simultaneity bias in migration models: An empirical examination, Demography 12 (3) (1975) 519-536.

URL http://www . jstor .org/stable/2060833

[55] ENTSO-E, ENTSO-E Transparency Platform (2019).

URL https://transparency.entsoe.eu/

\section{Appendix}

8.1. Addtional Tables 
Table 6: Variance Inflation Factors (VIF) for spring and summer for the specified model

\begin{tabular}{|c|c|c|c|c|c|c|c|}
\hline Hour & Solar & Wind & Gas price & $\mathrm{CH}$ load & $\mathrm{DE}+\mathrm{AT}$ load & FR load & IT load \\
\hline 1 & & 1,17 & 1,08 & 2,35 & 1,35 & 2,23 & 1,07 \\
\hline 2 & & 1,16 & 1,10 & 2,48 & 1,36 & 2,36 & 1,08 \\
\hline 3 & & 1,13 & 1,10 & 2,57 & 1,37 & 2,42 & 1,09 \\
\hline 4 & & 1,12 & 1,09 & 2,56 & 1,40 & 2,36 & 1,10 \\
\hline 5 & & 1,10 & 1,07 & 2,73 & 1,66 & 2,11 & 1,11 \\
\hline 6 & & 1,09 & 1,04 & 3,75 & 2,78 & 1,92 & 1,16 \\
\hline 7 & & 1,09 & 1,03 & 4,10 & 3,50 & 1,79 & 1,17 \\
\hline 8 & & 1,11 & 1,02 & 3,65 & 3,36 & 1,71 & 1,18 \\
\hline 9 & 1,14 & 1,27 & 1,03 & 3,20 & 3,06 & 1,67 & 1,15 \\
\hline 10 & 1,17 & 1,30 & 1,04 & 2,77 & 2,73 & 1,60 & 1,13 \\
\hline 11 & 1,19 & 1,35 & 1,05 & 2,73 & 2,82 & 1,57 & 1,12 \\
\hline 12 & 1,24 & 1,38 & 1,05 & 2,38 & 2,30 & 1,59 & 1,11 \\
\hline 13 & 1,23 & 1,37 & 1,04 & 2,56 & 2,51 & 1,61 & 1,12 \\
\hline 14 & 1,24 & 1,34 & 1,04 & 2,57 & 2,52 & 1,73 & 1,13 \\
\hline 15 & 1,24 & 1,34 & 1,03 & 2,55 & 2,47 & 1,81 & 1,13 \\
\hline 16 & 1,23 & 1,35 & 1,03 & 2,50 & 2,41 & 1,89 & 1,14 \\
\hline 17 & 1,24 & 1,32 & 1,03 & 2,26 & 2,09 & 1,90 & 1,14 \\
\hline 18 & 1,22 & 1,28 & 1,03 & 2,08 & 1,90 & 1,80 & 1,14 \\
\hline 19 & & 1,18 & 1,04 & 1,82 & 1,72 & 1,62 & 1,12 \\
\hline 20 & & 1,13 & 1,02 & 1,99 & 1,69 & 1,67 & 1,13 \\
\hline 21 & & 1,14 & 1,04 & 2,17 & 1,74 & 1,67 & 1,11 \\
\hline 22 & & 1,20 & 1,05 & 2,33 & 1,72 & 1,92 & 1,12 \\
\hline 23 & & 1,21 & 1,06 & 2,46 & 1,59 & 2,14 & 1,09 \\
\hline 24 & & 1,19 & 1,06 & 2,44 & 1,47 & 2,22 & 1,09 \\
\hline
\end{tabular}




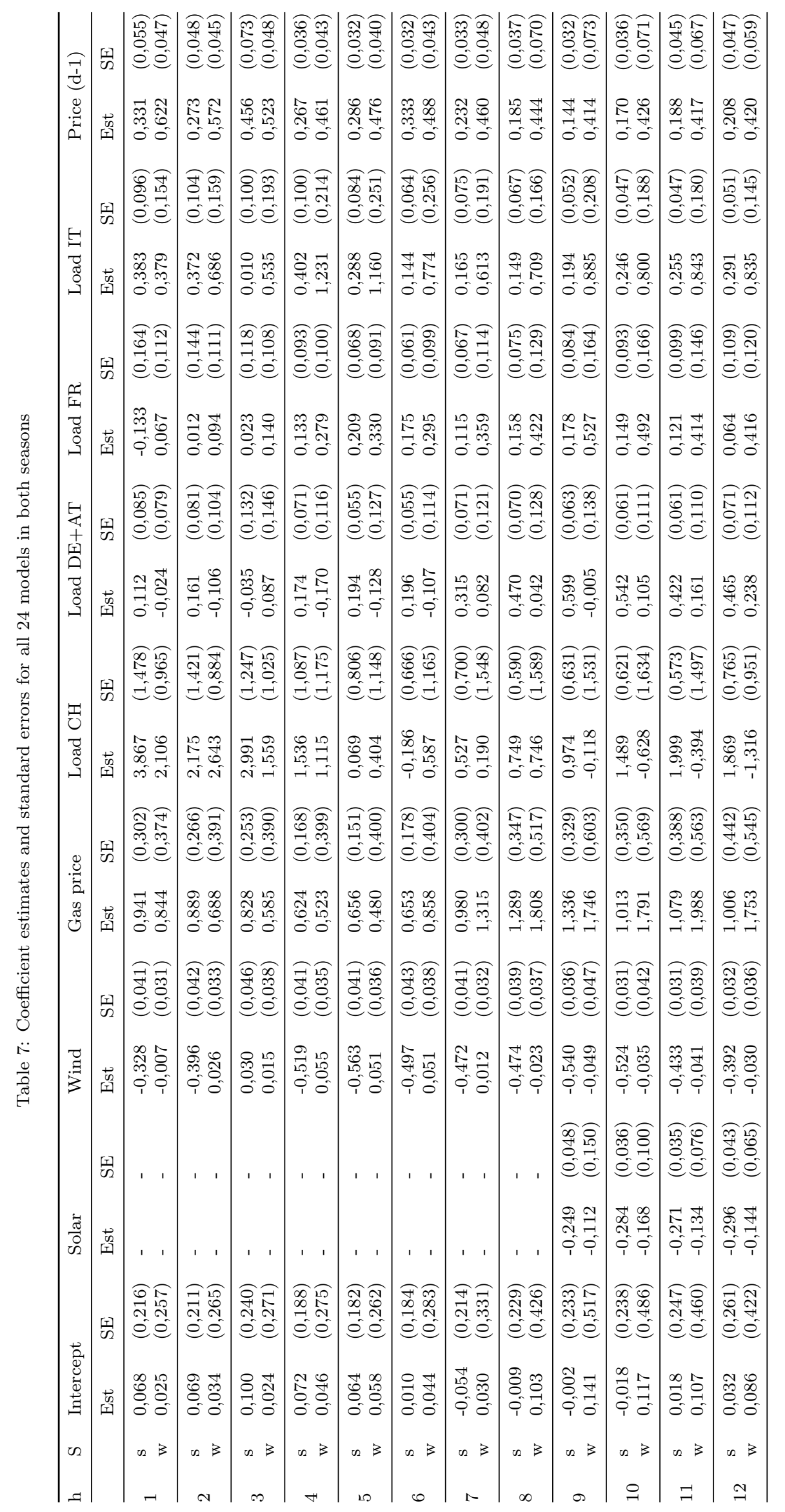




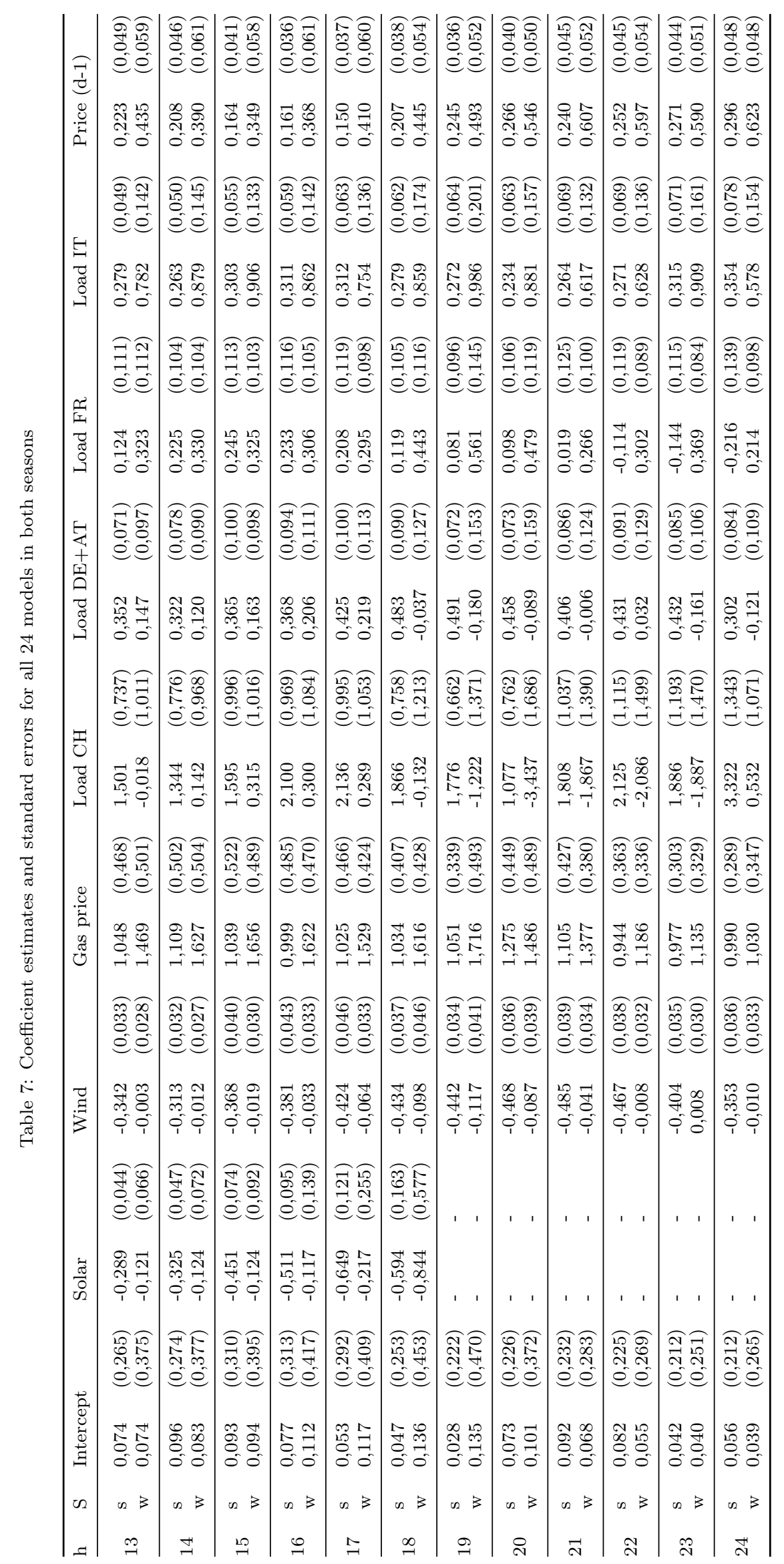




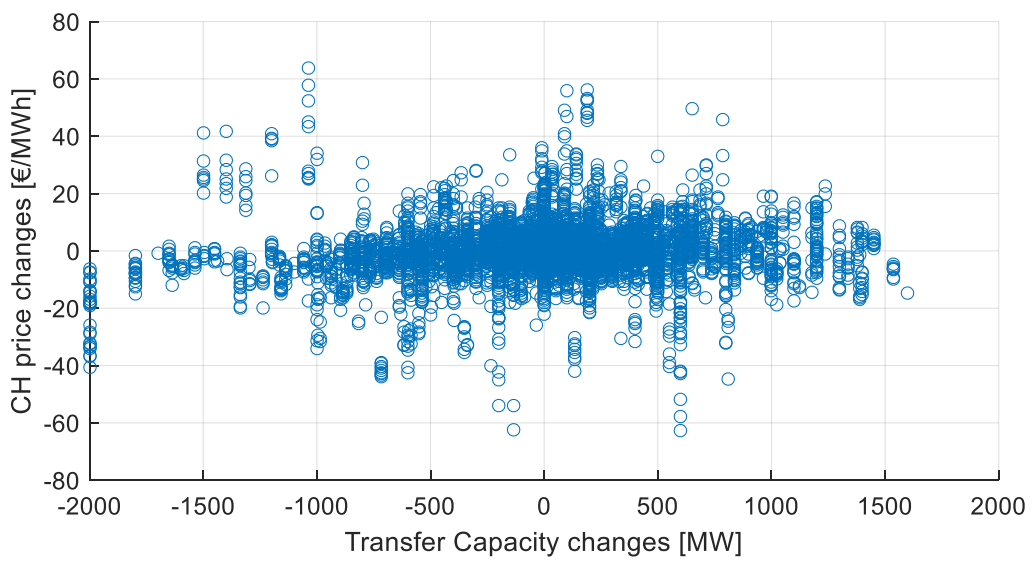

Figure 8: Scatter plot of the differences of transfer capacities from $\mathrm{CH}$ to $\mathrm{DE}$ and the differences of $\mathrm{CH}$ electricity prices

Table 8: Transmission line congestion events 2015 - 2017 (26304 hours). Numbers indicate the number of times the scheduled commercial flows across the borders equal or exceed the forcasted day-ahead transfer capacities.

\begin{tabular}{lcccc}
\hline & \multicolumn{2}{c}{ CH to Country } & \multicolumn{2}{c}{ Country to CH } \\
\hline DE & 0 & $(0 \%)$ & 2296 & $(8.63 \%)$ \\
FR & 8923 & $(33.92 \%)$ & 8860 & $(33.68 \%)$ \\
IT & 110 & $(0.42 \%)$ & 54 & $(0.21 \%)$ \\
\hline
\end{tabular}



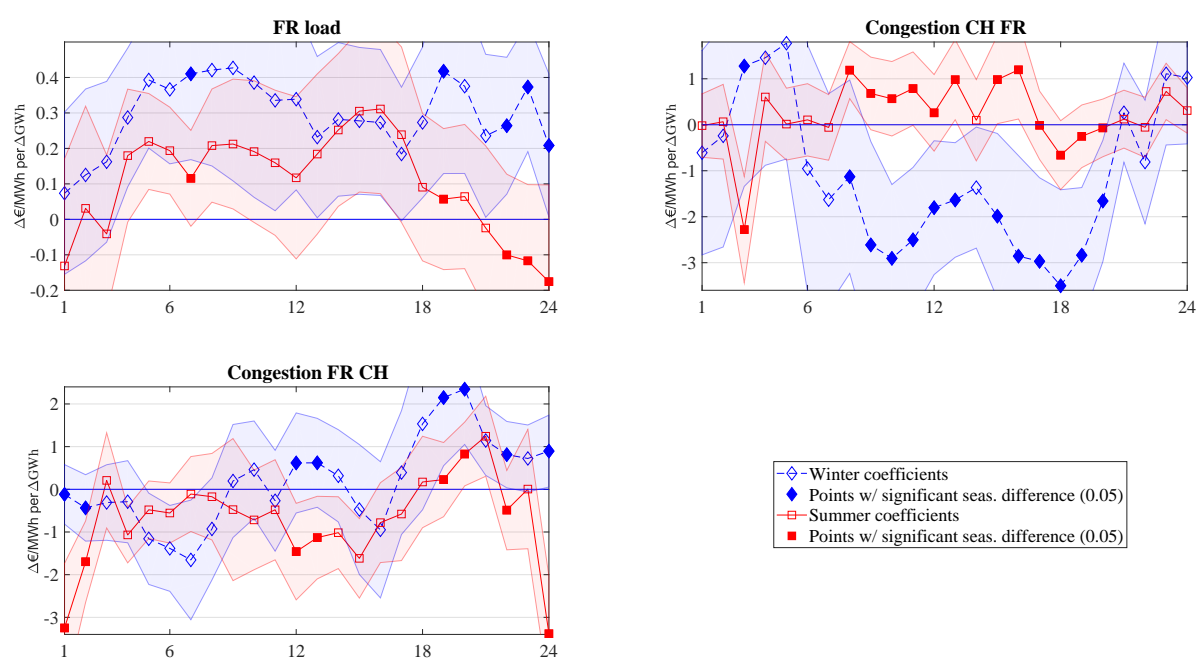

Figure 9: Coefficients of French load and transmission constraint dummy from additional model run. The influence of including dummies for transmission line utilization on all other coefficients is negligible. Compare also Table 8 All coefficients can be found in the supplement. 


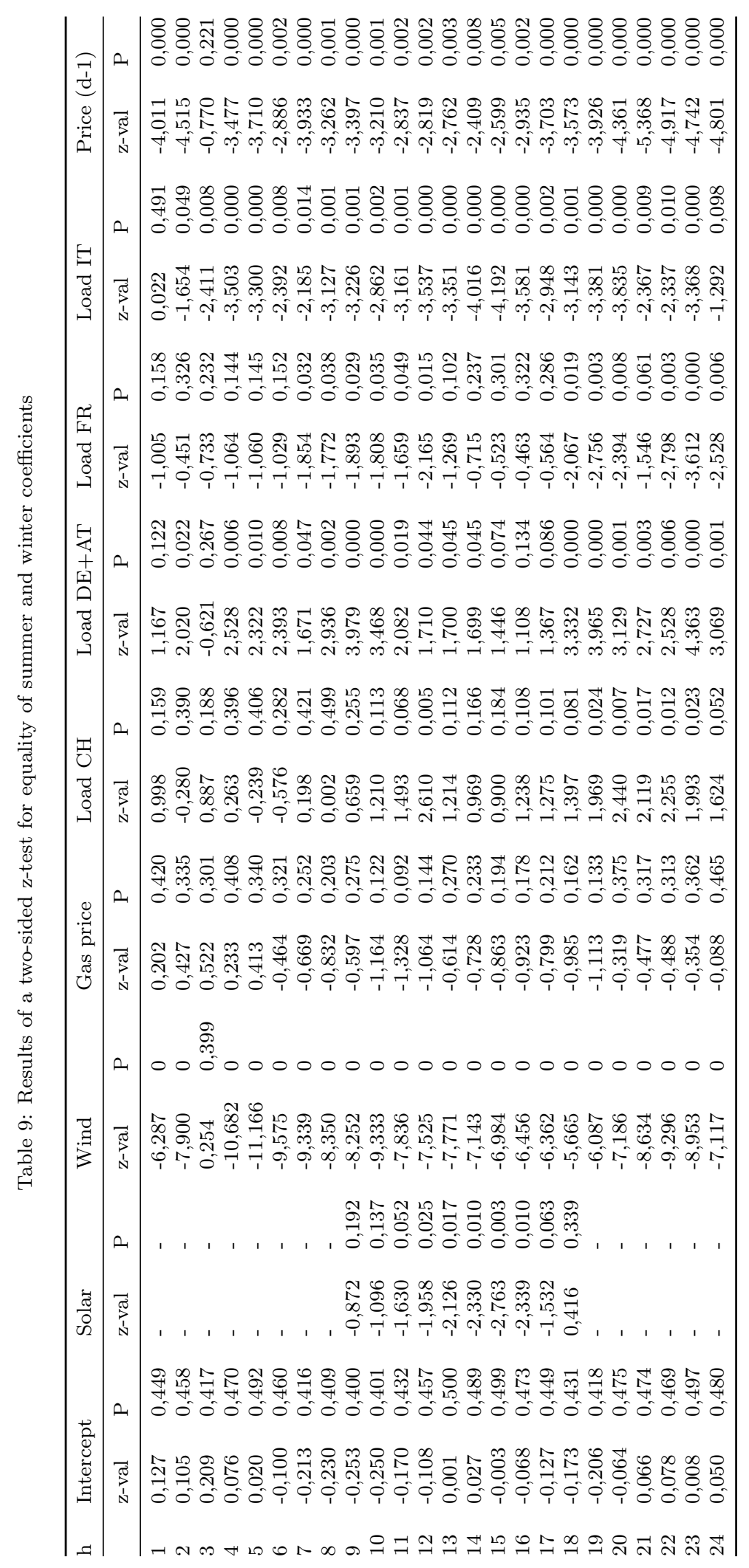


Table 10: Hourly net electricity imports from third-party countries into Germany as percentage of German domestic load

\begin{tabular}{|c|c|c|c|c|}
\hline Quantile & $\mathbf{2 5 \%}$ & $\mathbf{5 0 \%}$ & $\mathbf{7 5 \%}$ & $\mathbf{9 5 \%}$ \\
\hline $\mathbf{2 0 1 5}$ & $-7,8 \%$ & $-5,4 \%$ & $-3,0 \%$ & $0,9 \%$ \\
\hline $\mathbf{2 0 1 6}$ & $-7,6 \%$ & $-5,0 \%$ & $-2,2 \%$ & $1,8 \%$ \\
\hline $\mathbf{2 0 1 7}$ & $-7,6 \%$ & $-4,6 \%$ & $-1,7 \%$ & $2,3 \%$ \\
\hline $\mathbf{2 0 1 5 - 1 7}$ & $-7,7 \%$ & $-4,9 \%$ & $-2,1 \%$ & $1,9 \%$ \\
\hline
\end{tabular}

Table 11: Hourly net electricity imports from third-party countries into France as percentage of French domestic load

\begin{tabular}{|c|c|c|c|c|}
\hline Quantile & $\mathbf{2 5 \%}$ & $\mathbf{5 0 \%}$ & $\mathbf{7 5 \%}$ & $\mathbf{9 5 \%}$ \\
\hline $\mathbf{2 0 1 5}$ & $-10,0 \%$ & $-7,0 \%$ & $-4,0 \%$ & $-0,4 \%$ \\
\hline $\mathbf{2 0 1 6}$ & $-7,6 \%$ & $-4,2 \%$ & $-0,7 \%$ & $4,2 \%$ \\
\hline $\mathbf{2 0 1 7}$ & $-8,6 \%$ & $-5,0 \%$ & $-0,7 \%$ & $4,9 \%$ \\
\hline $\mathbf{2 0 1 5 - 1 7}$ & $-9,1 \%$ & $-5,7 \%$ & $-1,9 \%$ & $4,0 \%$ \\
\hline
\end{tabular}

\subsection{Mathematical description of the BEM model}

We present the mathematical formulation of the profit optimisation problem of each player and the distribution problem of the transmission system operator. Since the BEM model is formulated as an equilibrium model the different problems are solved simultaneously forming the complete mathematical program of the BEM model.

First, we give the nomenclature used in the mathematical formulations and then we describe in detail the profit optimisation problem of each player and the distribution problem of the transmission system operator.

\subsubsection{Nomenclature}

Table 1: Main indices

\begin{tabular}{|c|c|}
\hline Index & Description \\
\hline i & $\begin{array}{l}\text { Player } i=1 \ldots I \text { (in this version of the model players are the five modelled } \\
\text { countries) }\end{array}$ \\
\hline j & $\begin{array}{l}\text { Power plant } j=1 \ldots J \text { owned by a player and located in a node of the trans- } \\
\text { mission grid }\end{array}$ \\
\hline $\mathbf{k}$ & Transmission line between nodes, $k=1 \ldots K$ \\
\hline 1 & Load period (typical hour) $l=1 \ldots L$ \\
\hline $\mathbf{n}$ & $\begin{array}{l}\text { Transmission grid node } n=1 \ldots N \text { (in this version of the model the nodes are } \\
\text { the five modelled countries: Austria, Germany, France, Italy and Switzerland) }\end{array}$ \\
\hline s & Probabilistic scenario in the stochastic version of the model $s=1 \ldots S$ \\
\hline $\mathbf{z}$ & $\begin{array}{l}\text { Index representing a season when } z=1 \ldots 4 \text { or representing the complete year } \\
z=5\end{array}$ \\
\hline $\mathbf{Z}(\mathbf{z}, \mathbf{l})$ & Set containing all the load hours $l$ belonging to the season $z$ (or year if $z=5$ ) \\
\hline STG $(\mathbf{j})$ & Set containing all storage technologies $j$ \\
\hline $\operatorname{DSP}(\mathbf{j})$ & Set containing all dispatchable hydrothermal technologies $j$ \\
\hline $\operatorname{NSP}(\mathbf{j})$ & Set containining all non dispatchable technologies $j$ \\
\hline
\end{tabular}


Table 2: Main parameters of the model

\begin{tabular}{|c|c|c|}
\hline \multicolumn{2}{|c|}{ Parameter Unit } & \multirow{2}{*}{$\begin{array}{l}\text { Description } \\
\text { Risk free return available for player } i \text { representing a risk-free } \\
\text { investment alternative for a player (instead of investing in power } \\
\text { supply capacity) }\end{array}$} \\
\hline$\widetilde{\mathbf{r}_{\mathbf{i}}}$ & - & \\
\hline $\mathbf{b}_{\mathbf{i}}$ & MW & $\begin{array}{l}\text { Capital invested in risk free asset (instead of investing in power } \\
\text { supply capacity) }\end{array}$ \\
\hline$\delta_{\mathbf{s}}$ & & $\begin{array}{l}\text { Weight of probabilistic scenario } s \text { in the stochastic version of } \\
\text { the model }\end{array}$ \\
\hline $\mathbf{t}_{1}$ & Hours & Duration of load period $l$ \\
\hline $\mathbf{c}_{\mathrm{nijs}}$ & EUR/MWh & $\begin{array}{l}\text { Variable cost of player } i \text { and power plant } j \text { located at grid node } \\
n \text { in load period } l \text { and probabilistic scenario } s\end{array}$ \\
\hline$\widetilde{\mathbf{c}}_{\text {nijs }}$ & EUR/MW/yr. & $\begin{array}{l}\text { Annual investment and fixed O\&M cost for newly built power } \\
\text { plant } j \text { at node } n \text { for player } i \text { at a discount rate of } 5 \%\end{array}$ \\
\hline $\mathbf{u}_{\mathrm{nij}}^{\operatorname{los}}$ & $\%$ & $\begin{array}{l}\text { Proportional increase in specific fuel consumption at the mini- } \\
\text { mum stable operating level of power plant } j \text {, of player } i \text { located } \\
\text { at node } n\end{array}$ \\
\hline $\mathbf{u}_{\mathbf{j}}^{\text {sucost }}$ & $\begin{array}{l}\text { EUR/MW of } \\
\text { started capac- } \\
\text { ity }\end{array}$ & Start-up cost of power plant $j$ \\
\hline $\mathbf{u}_{\mathrm{nij}}^{\text {rucost }}$ & $\begin{array}{l}\mathrm{EUR} / \mathrm{MW} \\
\text { of increased } \\
\text { capacity }\end{array}$ & $\begin{array}{l}\text { Ramping up cost of power plant } j \text { of player } i \text { located at grid } \\
\text { node } n\end{array}$ \\
\hline $\mathbf{u}_{\mathrm{nij}}^{\mathrm{rdcost}}$ & $\begin{array}{l}\text { EUR/MW } \\
\text { of decreased } \\
\text { capacity }\end{array}$ & $\begin{array}{l}\text { Ramping down cost of power plant } j \text { of player } i \text { located at grid } \\
\text { node } n\end{array}$ \\
\hline $\mathbf{u}_{\text {nij }}^{\text {ruicost }}$ & $\begin{array}{l}\mathrm{EUR} / \mathrm{MW} \\
\text { of increased } \\
\text { capacity }\end{array}$ & $\begin{array}{l}\text { Ramping up cost during charging of storage } j \text { of player } i \text { located } \\
\text { at grid node } n\end{array}$ \\
\hline $\mathbf{u}_{\mathrm{nij}}^{\mathrm{rdicost}}$ & $\begin{array}{l}\text { EUR/MW } \\
\text { of decreased } \\
\text { capacity }\end{array}$ & $\begin{array}{l}\text { Ramping down cost during charging of storage } j \text { of player } i \\
\text { located at grid node } n\end{array}$ \\
\hline $\mathbf{u}_{\mathrm{nij}}^{\mathrm{mof}}$ & hours & Minimum offline time of power plant $j$ at node $n$ of player $i$ \\
\hline $\mathbf{u}_{\mathrm{nij}}^{\mathrm{mon}}$ & Hours & Minimum online time of power plant $j$ at node $n$ of player $i$ \\
\hline $\mathbf{u}_{\mathrm{nij}}^{\text {mop }}$ & & $\begin{array}{l}\text { Minimum stable operating level of power plant } j \text { at node } n \\
\text { owned by player } i\end{array}$ \\
\hline $\mathbf{x}_{\mathrm{nij}}^{\mathbf{0}}$ & MW & $\begin{array}{l}\text { Existing capacity of power plant } j \text { located at node } n \text { and owned } \\
\text { by player } i\end{array}$ \\
\hline $\mathbf{x}_{\mathrm{nij}}^{\max }$ & MW & $\begin{array}{l}\text { Maximum allowed investment of power plant } j \text { located at node } \\
n \text { from player } i\end{array}$ \\
\hline $\mathbf{f}_{\text {nijls }}^{\max }$ & $\begin{array}{l}\% \text { of installed } \\
\text { capacity }\end{array}$ & $\begin{array}{l}\text { Maximum availability factor of power plant } j \text { at node } n \text { owned } \\
\text { by player } i \text { in load period } l \text { and probabilistic scenario } s\end{array}$ \\
\hline $\mathbf{f}_{\text {nijls }}^{\min }$ & $\begin{array}{l}\% \text { of installed } \\
\text { capacity }\end{array}$ & $\begin{array}{l}\text { Minimum availability factor of power plant } j \text { at node } n \text { owned } \\
\text { by player } i \text { in load period } l \text { and probabilistic scenario } s\end{array}$ \\
\hline $\mathbf{u}_{\mathrm{nij}}^{\mathrm{ru}}$ & $\begin{array}{l}\% \text { of online ca- } \\
\text { pacity per hour }\end{array}$ & Ramping up rate of power plant $j$ at node $n$ of player $i$ \\
\hline $\mathbf{u}_{\mathrm{nij}}^{\mathrm{rd}}$ & $\begin{array}{l}\% \text { of online ca- } \\
\text { pacity per hour }\end{array}$ & Ramping down rate of power plant $j$ at node $n$ of player $i$ \\
\hline
\end{tabular}




\begin{tabular}{|c|c|c|}
\hline \multicolumn{2}{|c|}{ Parameter Unit } & \multirow{2}{*}{$\begin{array}{l}\text { Description } \\
\text { Operation level of power plant } j \text { at node } n \text { of player } i \text { above } \\
\text { which no part load efficiency losses occur }\end{array}$} \\
\hline $\mathbf{u}_{\mathrm{nij}}^{\operatorname{lup}}$ & $\%$ & \\
\hline $\mathbf{u}_{\mathrm{nij}}^{\mathbf{o}}$ & - & Energy-to-power ration of storage $j$ of player $i$ at node $n$ \\
\hline $\mathbf{u}_{\mathrm{nij}}^{\mathrm{in}}$ & - & $\begin{array}{l}\text { Ratio charging capacity to output capacity of storage } j \text { owned } \\
\text { by player } i \text { and located at node } n\end{array}$ \\
\hline $\mathbf{u}_{\mathrm{nij}}^{\mathbf{d}}$ & $\begin{array}{l}\% \text { of energy } \\
\text { storage capac- } \\
\text { ity }\end{array}$ & $\begin{array}{l}\text { Maximum depth of discharge of storage } j \text { at grid node } n \text { owned } \\
\text { by player } i\end{array}$ \\
\hline $\mathbf{u}_{\mathrm{nij}}^{\mathrm{seffi}}$ & $\%$ & $\begin{array}{l}\text { Charging efficiency of storage } j \text { at grid node } n \text { owned by player } \\
i\end{array}$ \\
\hline $\mathbf{u}_{\text {nij }}^{\text {seffo }}$ & $\%$ & $\begin{array}{l}\text { Discharging efficiency of storage } j \text { at grid node } n \text { owned by } \\
\text { player } i\end{array}$ \\
\hline $\mathbf{u}_{\text {nijls }}^{\text {inflow }}$ & MWh & $\begin{array}{l}\text { Water inflow in MWh entered in storage } j \text { at grid node } n \text { which } \\
\text { is owned by player } i \text { in load period } l \text { and probabilistic scenario } \\
s\end{array}$ \\
\hline $\mathbf{u}_{\mathrm{nij}}^{\mathrm{rui}}$ & $\begin{array}{l}\% \text { of online ca- } \\
\text { pacity per hour }\end{array}$ & $\begin{array}{l}\text { Ramping up rate of charging power of storage } j \text { at node } n \text { of } \\
\text { player } i\end{array}$ \\
\hline $\mathbf{u}_{\mathrm{nij}}^{\mathrm{rdi}}$ & $\begin{array}{l}\% \text { of online ca- } \\
\text { pacity per hour }\end{array}$ & $\begin{array}{l}\text { Ramping down rate of charging power of storage } j \text { at node } n \text { of } \\
\text { player } i\end{array}$ \\
\hline $\mathbf{u}_{\mathrm{nijls}}^{\mathrm{emax}}$ & MWh & $\begin{array}{l}\text { Maximum stored energy (potential) of storage } j \text { of player } i \text { at } \\
\text { node } n\end{array}$ \\
\hline $\mathbf{u}_{\mathrm{nijls}}^{\mathrm{emin}}$ & MWh & $\begin{array}{l}\text { Minimum stored energy (potential) of storage } j \text { of player } i \text { at } \\
\text { node } n\end{array}$ \\
\hline $\mathbf{u}_{\text {nijzs }}^{\text {avmax }}$ & $\begin{array}{l}\% \text { of installed } \\
\text { capacity }\end{array}$ & $\begin{array}{l}\text { Maximum utilisation rate of power plant } j \text { of player } i \text { at node } \\
n \text { in season } z \text { (or year when } z=5 \text { ) and probabilistic scenario } s\end{array}$ \\
\hline $\mathbf{u}_{\mathrm{nijzs}}^{\text {avmin }}$ & $\begin{array}{l}\% \text { of installed } \\
\text { capacity }\end{array}$ & $\begin{array}{l}\text { Minimum utilisation rate of power plant } j \text { of player } i \text { at node } n \\
\text { in season } z \text { (or year when } z=5 \text { ) and probabilistic scenario } s\end{array}$ \\
\hline $\mathbf{u}_{\text {nijzs }}^{\mathrm{qmax}}$ & MWh & $\begin{array}{l}\text { Maximum allowed production from power plant } j \text { of player } i \\
\text { at node } n \text { in season } z \text { (or year when } z=5 \text { ) and probabilistic } \\
\text { scenario } s\end{array}$ \\
\hline $\mathbf{u}_{\mathrm{nijzs}}^{\mathrm{qmin}}$ & MWh & $\begin{array}{l}\text { Minimum (must run) production from power plant } j \text { of player } \\
i \text { at node } n \text { in season } z \text { (or year when } z=5 \text { ) and probabilistic } \\
\text { scenario } s\end{array}$ \\
\hline $\mathbf{t}_{\mathbf{k}}^{\max }$ & MW & Bound on transmission capacity in line $k$ \\
\hline $\mathbf{t}_{\mathbf{k}}^{\min }$ & MW & Bound on transmission capacity in line $k$ (opposite direction) \\
\hline$\widetilde{\mathbf{p}}_{\mathrm{nk}}$ & - & $\begin{array}{l}\text { Power transfer distribution factor (PTDF) of node } n \text { and power } \\
\text { line } k\end{array}$ \\
\hline $\mathbf{v}_{\mathbf{n}}^{\mathbf{R E S}-}$ & $\%$ & Downward variation of the residual load curve in node $n$ \\
\hline $\mathbf{v}_{\mathbf{n}}^{\mathrm{RES}+}$ & $\%$ & Upward variation of the residual load curve in node $n$ \\
\hline $\mathbf{v}_{\text {nijls }}^{\mathbf{N S P}-}$ & $\%$ & $\begin{array}{l}\text { Downward variation of the production of the non dispatchable } \\
\text { technology } j \text {, of player } i \text {, in node } n \text { and load period } l\end{array}$ \\
\hline $\mathbf{v}_{\text {nijls }}^{\mathbf{N S P}+}$ & $\%$ & $\begin{array}{l}\text { Upward variation of the production of the non dispatchable tech- } \\
\text { nology } j \text {, of player } i \text {, in node } n \text { and load period } l\end{array}$ \\
\hline
\end{tabular}

Table 3: Main variables of the model 


\begin{tabular}{|c|c|c|}
\hline Variable & Unit & Description \\
\hline $\mathbf{p}_{\text {nls }}$ & EUR/MWh & Electricity price in node $n$, load period $l$ and probabilistic scenario $s$ \\
\hline $\mathbf{q}_{\mathrm{nijls}}$ & MWh & $\begin{array}{l}\text { Quantity of power produced in node } n \text {, by player } i \text {, from power plant } j \text {, } \\
\text { load period } l \text { and probabilistic scenario } s\end{array}$ \\
\hline $\mathbf{q}_{\mathrm{nijls}}^{\mathrm{in}}$ & MWh & $\begin{array}{l}\text { Quantity of power stored in node } n \text {, by player } i \text {, storage plant } j \text {, load } \\
\text { period } l \text { and probabilistic scenario } s\end{array}$ \\
\hline $\mathbf{w}_{\text {nijls }}^{\mathbf{u}}$ & MW & $\begin{array}{l}\text { Start-up capacity of power plant } j \text { of player } i \text { at node } n \text { in load period } \\
l \text { and probabilistic scenario } s\end{array}$ \\
\hline $\mathbf{w}_{\text {nijls }}^{\mathbf{d}}$ & MW & $\begin{array}{l}\text { Shutdown capacity of power plant } j \text { of player } i \text { at node } n \text { in load period } \\
l \text { and probabilistic scenario } s\end{array}$ \\
\hline $\mathbf{w}_{\text {nijls }}^{\mathbf{o}}$ & MW & $\begin{array}{l}\text { Offline capacity of power plant } j \text { of player } i \text { at node } n \text { in load period } l \\
\text { and probabilistic scenario } s\end{array}$ \\
\hline $\mathbf{q}_{\text {nijls }}^{\mathbf{u}}$ & MWh & $\begin{array}{l}\text { Increase in the production of power plant } j \text { of player } i \text { located at node } \\
n \text { in load period } l \text { and probabilistic scenario } s\end{array}$ \\
\hline $\mathbf{q}_{\mathrm{nijls}}^{\mathbf{d}}$ & MWh & $\begin{array}{l}\text { Decrease in the production of power plant } j \text { of player } i \text { located at node } \\
n \text { in load period } l \text { and probabilistic scenario } s\end{array}$ \\
\hline $\mathbf{q}_{\text {nijls }}^{\mathrm{ui}}$ & MWh & $\begin{array}{l}\text { Increase in charging power of storage } j \text { of player } i \text { located at node } n \text { in } \\
\text { load period } l \text { and probabilistic scenario } s\end{array}$ \\
\hline $\mathbf{q}_{\mathrm{nijls}}^{\mathrm{di}}$ & MWh & $\begin{array}{l}\text { Decrease in charging power of storage } j \text { of player } i \text { located at node } n \text { in } \\
\text { load period } l \text { and probabilistic scenario } s\end{array}$ \\
\hline$\overline{\mathbf{c}}_{\text {nijs }}$ & $\mathrm{EUR} / \mathrm{MW} / \mathrm{yr}$ & $\begin{array}{l}\text { Annual costs of battery } j \text { at node } n \text { for player } i \text { at a discount rate of } \\
5 \% \text {, simulating replacement of the battery because it has exceeded its } \\
\text { cycling lifetime }\end{array}$ \\
\hline $\mathbf{x}_{\mathrm{nij}}$ & MW & Investment in power plant $j$ at node $n$ from player $i$ \\
\hline $\mathbf{q}_{\text {nijls }}^{\mathbf{l}}$ & MWh & $\begin{array}{l}\text { Loss of production due to part load operation of power plant } j \text { of player } \\
i \text { at node } n \text {, load period } l \text { and probabilistic scenario } s\end{array}$ \\
\hline $\mathbf{e}_{\text {nijls }}$ & MWh & $\begin{array}{l}\text { Stored energy in storage } j \text { at grid node } n \text { owned by player } i \text { in load } \\
\text { period } l \text { and probabilistic scenario } s\end{array}$ \\
\hline $\mathbf{a}_{\mathrm{nls}}$ & MWh & $\begin{array}{l}\text { Import into node } n \text {, load period } l \text { and probabilistic scenario } s \text { (exports } \\
\text { have a negative sign) }\end{array}$ \\
\hline $\mathbf{d}_{\mathrm{nls}}$ & MWh & $\begin{array}{l}\text { Electricity demand of power in node } n \text {, load period } l \text { and probabilistic } \\
\text { scenario } s\end{array}$ \\
\hline
\end{tabular}

\subsubsection{Profit optimisation problem of each player}

Each player in the model maximises its profit concurrently. The model does not have a single objective function, but each player has its own objective function. Each player optimises the net profit (eq. 1), which consists of the operational profit, losses from the wear-down of the equipment (e.g. by exceeding the cycling life of batteries), fixed O\&M costs, and capital costs of the investments. The fixed costs of the existing power plants is an add-on term in the objective function and can be neglected for the equilibrium solution. The operational profit is the sum of the profit in each grid node and each power plant in a load period (in the stochastic version of the model there is an additional sum over the probabilistic scenarios - and in this context the expected operational profit of each player is maximised). The operating profit in each load period, in each grid node and for each power plant is the revenues of selling power minus the total of variable costs (i.e. fuel costs, variable O\&M and taxes). The optimisation of the net profit is subject to a number of technical and market constraints, which are described below in detail. 


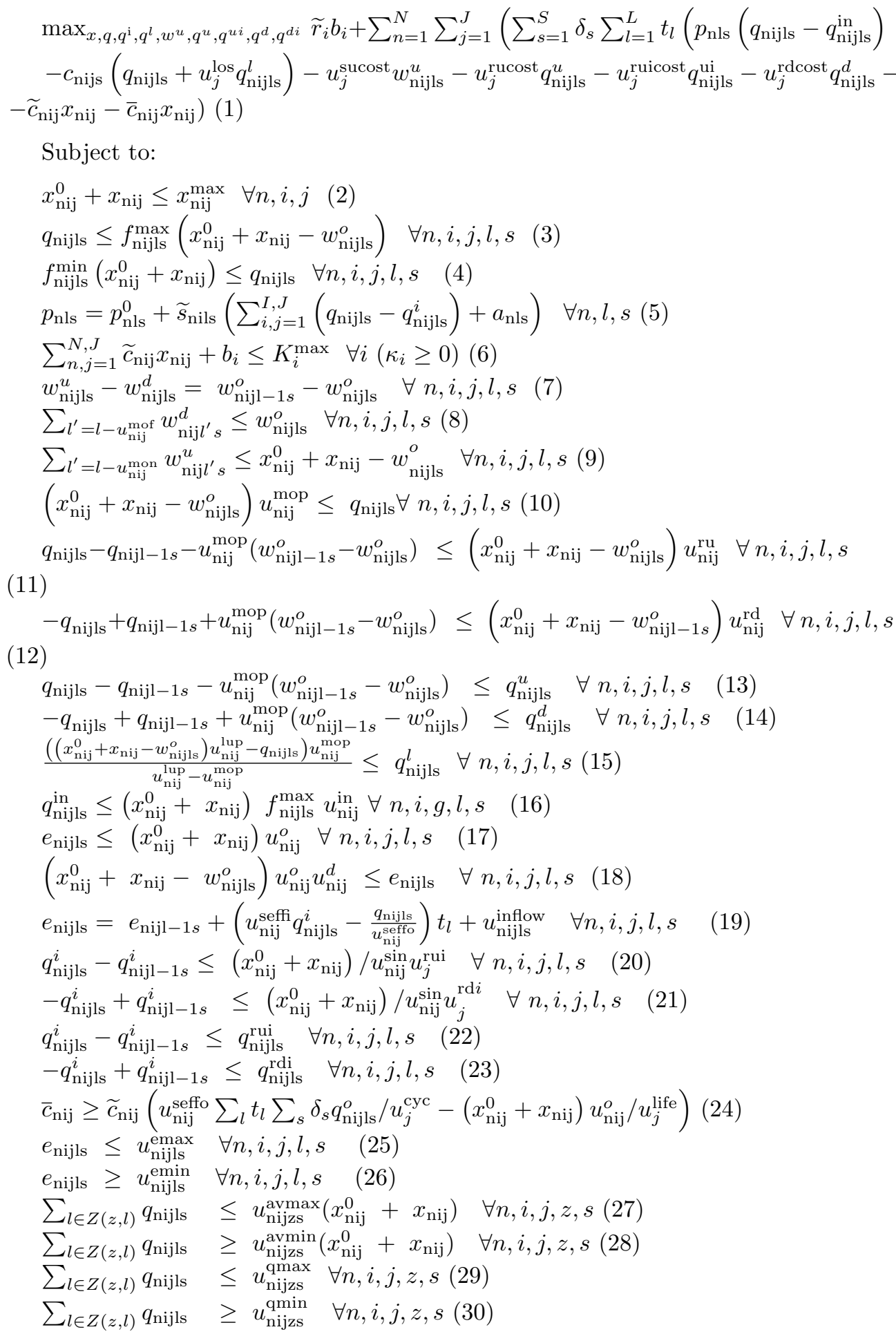

Eq. 2 represents the feasible potential of total capacity that limits the allowed investment of a power plant $j$ located at node $n$ and owned by player $i$. This 
constraint is applied to renewables that have limited potential and to conventional thermal technologies that are limited by policy constraints (e.g. nuclear power plants).

Eq. 3 states that the quantity produced in a load period from a power plant cannot exceed the available capacity of the power plant in each hour. Eq. 4 introduces a minimal running constraint based on a minimal availability factor if applicable

Eq. 5 represents the linear inverse demand function through which the dayahead market is modelled. This equation gives the equilibrium price at a node $n$, in load period $l$ and probabilistic scenario $s$.

Eq. 6 limits the available financial capital which can be used in investment in supply technologies or alternatively for a risk-free financial asset (player's budget constraint).

To reduce problem size and achieve manageable computation times, a continuous relaxation of the unit commitment problem is coupled to the investment problem of eqs. (2)-(6). Equation (7) implements the unit commitment logic, by requiring the online capacity to be changed by starting up offline units or shutting down online units.

Eq. 8 implements the minimum offline time constraint requiring that the amount of offline capacity that can start up to be limited to the capacity that is offline for at least the minimum downtime of the power plant $j$ located at node $n$ and owned by player $i$. Similarly, eq. 9 implements the minimum online time by requiring that the amount of online capacity that can shut down to be limited to the capacity that it is online at least the minimum online time of power plant $j$.

Eq. 10 imposes the minimum stable operating level constraint, by requiring that the start-up capacity of power plant $j$ has to reach the minimum stable operating level at least, and then it should operate at least at this level until it is shut down.

Eq. 11 and eq. 12 set the ramping up (eq. 11) and ramping down (eq. 12) constraints. In order to be able to account for ramping costs, two auxiliary non-negative variables are used to hold the amount of capacity that is increased (ramping up) or decreased (ramping down), according to eq. 13 and eq. 14 respectively. These auxiliary variables are then multiplied by the corresponding ramping costs in the objective function (eq. 1).

The efficiency loss in part load operation is approximated via the "production loss" (or "additional production"). A linear function calculates the "production loss" between the minimum stable operating level and a load level above which no part load efficiency losses occur. Then this "production loss" results in increased fuel consumption, though which the part load efficiency losses are captured (eq. 15). It is important to note that the "additional production" or "production loss" that results increased fuel consumption does not enter in any other equation of the model than the objective function (in which it is multiplied by the production cost $\mathbf{c}_{\text {nijs }}$.

Electricity storage systems, e.g. batteries, pump hydro storage and compressed air storage, are subject to energy buffer dynamics, exogenous inflows (for hydro storage) and limited cycle life (for batteries). Non-symmetrical charge and discharge power ratings are allowed. In the model, a storage system is defined in terms of its charging and discharging power, as well as its energy to power ratio. 
Eq. 16 sets the maximum charging power allowed for storage $j$ given its output capacity $\left(x_{n i j}^{0}+x_{n i j}\right)$. This equation allows for asymmetrical treatment of the charging and discharging power ratings, e.g. for pump hydro storage.

Eq. 17 defines the maximum stored energy of a storage technology, with respect to its discharging capacity and the specific energy-to-power ratio. Also, there could be a limit on how deeply a storage system can be discharged, in order not to shorten the cycle life (especially for batteries) or due to water management constraints (for pump hydro storage). This limit is imposed by eq. 18, which represents the depth of discharge constraint.

Eq. 19 defines the energy balance equation for a storage option $j$. At each load hour the energy stored should be equal to the energy stored in the previous hour minus the output from the storage plus the charging. For pump hydro storage the water inflow at a given load period $l$ are also taken into account via the exogenous parameter $u_{\text {nijls }}^{\text {inflow }}$.

Ramping constraints regarding the output of a storage $j$ are modelled via the equations 13 and 14 . The ramping constraints regarding the charging power rate of a storage $j$ are additionally modelled via eqs. 20 (ramping up of charging power) and 21 (ramping down of charging power). Similarly to the hydrothermal power plants, there are also auxiliary variables holding the ramping up quantity (eq. 22) and the ramping down quantity (eq. 23) of the charging power that in turn enter into the objective function to account for the charging related ramping costs.

We also impose a constraint imposing a targeted maximum cycling rate of a storage throughout its lifetime. If the actual cycling rate of the storage is lower than or equal to this targeted cycle rate then the additional cost due to the wear of the storage and its replacement is zero, otherwise it is positive according to eq. 24.

Additional constraints can be imposed regarding the maximum (eq. 25) and minimum (eq. 26) levels of stored energy. Finally, additional constraints can be also imposed regarding the seasonal or annual production from power plants, either as lower or upper bounds (equations 27-28 impose constraints on seasonal/annual utilisation rates and eqs. 29-30 impose constraints on the level of production).

\subsubsection{Distribution problem of the Transmission System Operator (TSO)}

The TSO's problem is a DC power flow problem with implicit auction, which can be seen as an approximation of today's more complex trading schemes. As stated in the main text, in a market equilibrium the different concepts of explicit and implicit auctions should converge and in the bilateral trade between nodes (producers and consumers) is equivalent in an equilibrium market solution to a central TSO that redistributes electricity among the nodes as a price taker.

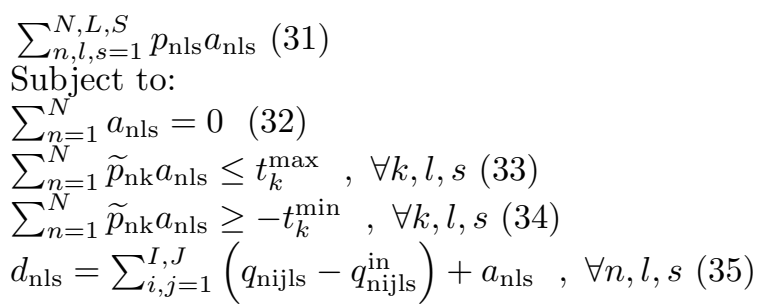




$$
\begin{aligned}
& \sum_{i} \sum_{j \in S T G} u_{\mathrm{nijls}}^{\mathrm{avmax}}\left(x_{\mathrm{nij}}^{0}+x_{\mathrm{nij}}\right) \geq \sum_{i}\left(\sum_{j \in D S P} u_{\mathrm{nijls}}^{\mathrm{avmax}}\left(x_{\mathrm{nij}}^{0}+x_{\mathrm{nij}}\right)-\left(1-v_{n}^{R E S-}\right)\right. \\
& \left.\left(\sum_{j \in D S P} q_{\mathrm{ijnls}}+\sum_{j \in S T G}\left(q_{\mathrm{ijnls}}-q_{\mathrm{ijnls}}^{\mathrm{in}}\right)\right)+\sum_{j \in N S P} v_{\mathrm{nijls}}^{\mathrm{NSP}+} q_{\mathrm{ijnls}}\right)(36) \\
& \sum_{i}\left(\sum_{j \in \mathrm{STG}} u_{\mathrm{nijls}}^{\mathrm{avmax}}\left(x_{\mathrm{nij}}^{0}+x_{\mathrm{nij}}\right)+\sum_{j \in \mathrm{DSP}} u_{\mathrm{nijls}}^{\mathrm{avmax}}\left(x_{\mathrm{nij}}^{0}+x_{\mathrm{nij}}\right)\right) \geq \sum_{i}\left(\left(1+v_{n}^{\mathrm{RES}+}\right)\right. \\
& \left.\left(\sum_{j \in \mathrm{DSP}} q_{\mathrm{ijnls}}+\sum_{j \in \mathrm{STG}}\left(q_{\mathrm{ijnls}}-q_{\mathrm{ijnls}}^{\mathrm{in}}\right)\right)+\sum_{j \in \mathrm{NSP}} v_{\mathrm{nijls}}^{\mathrm{NSP}} q_{\mathrm{ijnls}}\right)(37)
\end{aligned}
$$

Eq. 31 defines the objective function of the TSO which is a dummy objective function maximising the profit from the distribution of electricity. But because eq. 32 does not allow arbitrage from TSO, actually the TSO optimises the social welfare by redistributing electricity to nodes in need.

Eq. 33 and eq. 34 define the grid transmission constraints via DC power flow modelling. The PTDF factor $\widetilde{p}_{\text {nk }}$ determines how much an import/export amount $a_{\mathrm{nls}}$ induces a power flow in the line $k$.

Eq. 35 determines the electricity demand in a node for a given load period and probabilistic scenario, which is equal to the production in the node minus what is used for charging storages, plus the imports and minus the exports $\left(a_{\text {nls }}\right.$ is negative when corresponds to exported quantities)

Eq. 36 states that the storage capacity must accommodate exogenously given downward variation $v_{R E S, n}^{-}$of the residual load curve $\left(\sum_{j \in D S P} q_{\mathrm{ijnls}}+\sum_{j \in S T G}\left(q_{\mathrm{ijnls}}-q_{\mathrm{ijnls}}^{\mathrm{in}}\right)\right)$, and exogenously given upward variation $v_{N S P, i, j, n}^{+}$of the non-dispatchable generation. The equation applies to each node. Therefore, this constraint ensures that there is enough storage capacity to absorb excess supply from renewables in some hours.

Eq. 37 imposes a peak constraint by requiring the dispatchable peak load capacity to accommodate exogenously given upward variation $v_{R E S, n}^{+}$of the residual load curve and downward variation $v_{N S P, i, j, n}^{+}$of the non-dispatchable generation. The equation applies to each node. Therefore, this constraint imposes a peak reserve margin.

The two security of supply constraints described by (eq. 36) and (eq. 37) are imposed because of the aggregation of the real load curve into 96 typical operating hours. Hence, conditions that are observed in the actual load curve of a 8760-hours resolutions are missed when aggregated to 96-hours. We therefore include for each average value of each one of the 96 hours its variability statistically estimated from 10-year sample of 8760 hours each.

The above problems, the players' problem and the TSO problem, are formulated as an open-loop mixed complementarity problem (MCP) and are solved simultaneously. 